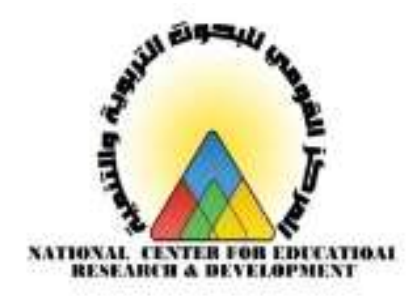

\title{
خصائص المعرفة القائمة على البحث العلمي (دراسة تطبيقية على هناهج اللغة العربية)
}

\author{
Sldes_e! \\ أ.م.د/أيمن عيد بكري محمد انيا عبد الرحمن دسوقي الأخرس

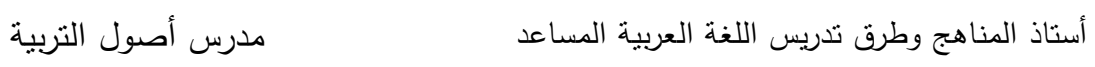 \\ بالمركز القومي للبحوث التربوية والتنمية بالمركز القومي للبحوث التربوية والتتمية
}

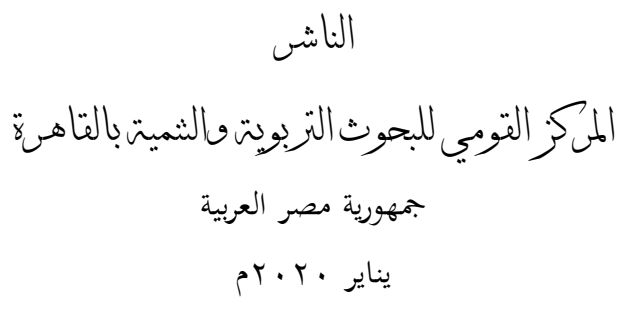




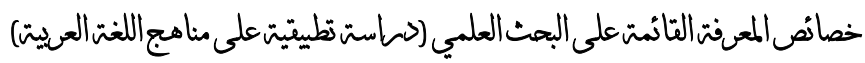

\section{هذص البمث}

يهدف البحث إلى تحديد مدى اشتمال مقررات اللغة العربية في الصفوف الأول والسادس الابتدائي والثالث الإعدادي والثالث الثانوي على خصائص المعرفة القائمة على البحث

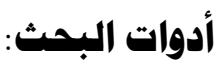

- استمارة تحليل محتوى مقرر اللغة العربية في ضوء خصائص المعرفة القائمة على

البحث العلمي.

سـار تحليل كتب اللغـة العربية كالتالي: تحديد كتب اللفـة العربيـة التـي سـيتم تحليلهاوتحديد وحدات التحليل وفئاته وإجـراء عمليـة التحليل ورصد النتائج وإجراء التحليل الإحصائي واستخراج المؤثرات الخاصة بالتحليل.

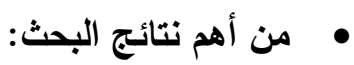

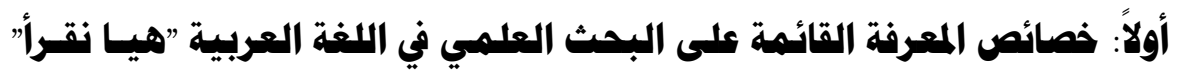

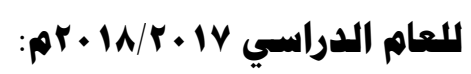

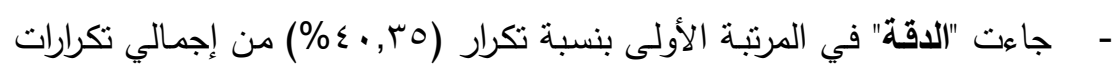

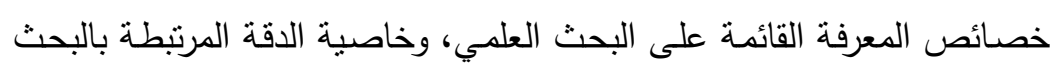
العلمي لم تتعد الثكل الظاهري فقط.

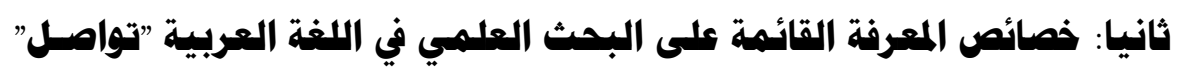

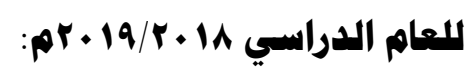

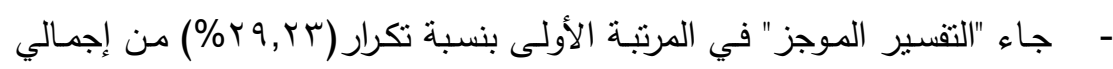

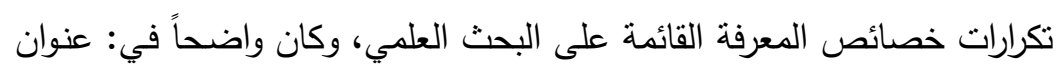
الكتاب ككلمة" تواصل" وعنوان الوحدة "من أكون"، وكان من المفترض الاهتمام الهمان

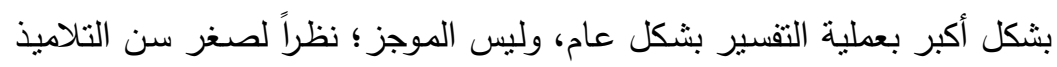

$$
\text { في هذه المرحلة. }
$$

.ร) $\leqslant$.

البحث التريوي 
المركن القومي للبحوث التبويةوالتنمية

\section{Characteristics of Knowledge based on Scientific Research (Applied Study on the Arabic Language Curriculum) Dr / Ayman Eid Bakry Dr / Rania Abd El Rahman Desoky Abstract}

The aims of the Research was to determine to what extent is the inclusion of the Arabic courses in the First and Sixth grades in primary stage and third preparatory, and the Third secondary stage on the characteristics of knowledge based on scientific research.

\section{Tools of the research:}

Content analysis form of the Arabic language course in light of the characteristics of the knowledge based on scientific research.

The analysis of the Arabic language books went as follows:

-Determining the Arabic language books which will be analyzed, and determining the units of the analysis and its categories, and perform the analysis process, and monitoring and scheduling the results, and the statistical analysis of the results and extracting the indicators of the analysis.

Among the results of the results of the research are:

-First: Characteristics of knowledge based on scientific research in the Arabic language "Let's Read" for the scholastic year 2017/2018.

-"Accuracy" came in the first rank with a repetitive ratio (\% 40.35) of the total repetitions of the characteristics of knowledge based on scientific research, the characteristics of the accuracy related to the scientific research was only the virtual shape.

- Second: The characteristics of knowledge based on scientific research in the Arabic language continues to the scholastic year 2018/2019:

-The brief explanation became in the first rank with a repetitive ratio of (\% 29.23) of a total repetitions of the characteristics of knowledge based on the scientific research, and it was clear in the title of the book like the word " communication" and the title of the unit "Who Am I", and it was expected to care ore and give more importance to the process of explanation in a general way due to the students in this stage. 


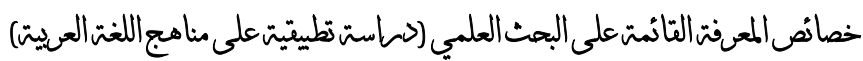

\section{خصائص المهرفة القائمة على البمث المهاثمي \\ (دراسة تطبيقية على هناهجه اللانة العربية)}

د/ رانيا عبد الرحمن دسوقي الأخرس

$$
\text { مدرس أصول التربية }
$$

بالمركز القومي للبحوث التربوية والتتمية
أ.م.د// أيمن عيد بكري محمد

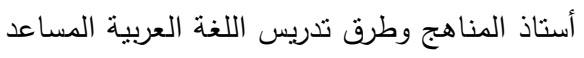

بالمركز القومي للبحوث التربوية والتنمية

\section{هقدمة:}

البحث العلمي من أهم عناصر التقدم في المجتمعات، بما يحققه دن تتمية

لجميع مجالات الحياة، فتقوم بـه المجتمعات وبـه تنهض، بـل يقاس مدى إمكانيـة التطور فيها بمدى إمكانيـة تحقيقها للبحث العلىي الفَّال في مجـالات الصـناعة والزراعـة والتكنولوجيا والتعليم، ويقوم البحث العلمي على المعرفة الحقيقيـة القادرة على تقويته وممارسته بشكل سليم ومثـر، المعرفة التي تُكَّن البحث العلمي من تحقيق نتائج واضحة ونهائية في مجالات الحياة المختلفة.

وللمعرفة خصـائص تقوم وتستمد ذاتها من البحث العلمي كالموضـوعية

والدقة والتحقق والإمبريقية والتقسير الموجز والتقكير الاحتمالي؛ لأنَّ البحث العلمي يتميز أيضًا بهذه الخصائص، إذن فالعلاقة مركبة بين المعرفة والبحث العلمي، كما يمكن القول بأنَّهـ بمكن تطوير البحث العلمي عن طريق الاهتمام بتحقيق وتفعيل هذه الخصائص.

كمـا أنَّ البحــث العلمسي فـي جميـع المجـالات عمليـة مسـتمرة متفاعلـة ديناميكيـة، قائم على تراكم العلم مـع المعرفـة مـع مـرور الوقت، وتعتمد مؤسسـات 


\section{المركن القومي للبحوث التبويةوالتنمية}

البحث العلمي على مجتمع من الباحثين مسترشد بمجموعة من المبادئ التي ثقوم عليها جميع البحوث العلمية (26-NRC, 2002, 25) وتداخل المعرفة في كل نـواحي ومجـالات المجتمـع واضـح؛ حتى أصـبح الاقتصـاد العـادل والمسـتـام هـو الاقتصاد القائم على المعرفة، وأنَّ هناك تتمية قائمسة على المعرفة كثقافة اقتصادية جديدة (Carrillo, 2015)؛ والدول المتقدمة التي أعطت البحث العلمي عنايـة فائقة وجعلته ضمن أولويات اهتماماتها استطاعت أنْ تحصد العديد من مخرجاته وتطبقه في الكثير من احتياجات المجتمع كعامل وقائي وعلاجي، لما يواجهه المجتمع من مشـكلات منتوعـة اقتصـادية واجتماعيـة.(الوذينانى، V . . Y، ع Y) ولـذا تـولي دول العالم المتقدم عناية كبيرة بتفعيله، خاصـة في أكثر المجالات تأنثراً في المتعلم وهو

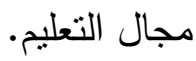

وتقوم المدرسة بدور مهم في تحقيق التربية والتعليم والتقيف وكل من هذه

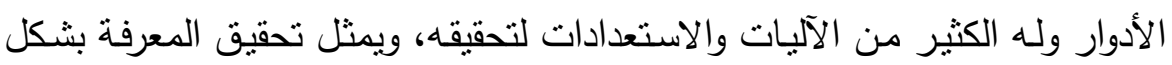
فعَّال العامـل المشـترك بين كل هذه المهام، وخاصـة تلك المعرفـة التي يجب أنْ يمنلكها المعلمون. ومنها: معرفة المحتوى التربوي ومعرفة المناهج الدراسية، ومعرفة الموضوع وبنيته التتظيمية.(Rollnick, 2017) ويتميز البحث العلمي في في التعليم بتوفير التعلم عن طريـق العمل والبحث التجريبي والتطوير؛ بقياس تعلم الطالب في الفصول الدراسية، باستخدام الأسـاليب المتتوعة من حكم المعلم وإجراء البحـوث أو القـرارات المتعلقة بـالأمور التعليميـة(Hegarty,2001,16)، لذا ينبغي إكساب التلاميذ القدرات البحثية وتعزيزها لإعدادهم للوظائف أو التقارير المستقبلية؛ ولاختبـار صـلاحية الأدوات أو الإجـراءات أو التجـارب؛ ولكـى يتحقـق ذلـك فيلـزم 


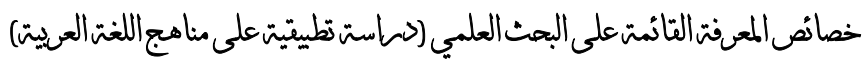

الطـلاب بنـاء قاعدة حقيقيـة للمعرفـة تمكنهم مـن الرجوع لهـا.(وزارة التربيـة والتعليم

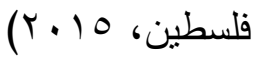

والمقررات الدراسية في التعليم قبل الجامعي وثثقة رسمية للتعليم، يلتزم بها المعلمون بأفكارها وموضوعاتها، وإن اختلفت طريقة التدريس التي يستخدمونها في تحقيق ذلك، وينبغي أن تكون مبنيـة على المعرفـة العلمية والبحث العلمي، وتقوم بدور فعّال في إكساب التلاميذ مهاراته، ومقررات اللغة العربية واحدة منها. والبحـث الحسالي يحلـل مقررات اللغـة العربيـة بهدف الوقوف على مـدى تضمينها لخصائص المعرفة القائمة على البحث العلمي.

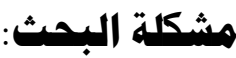

مهارات التفكير العلمي والبحث العلمي تعتبر موضوعًا ومهارات للحياة يتعلمها الطـلاب ويمارسونها في حياتهم التعليميـة والحيـاة اليوميـة، ولا تتوقف عمـا يدرسه الطلاب ويتعلمونه، ولأن المقررات الدراسية للغة العربية في المراحل التعليمية إطـار متكامـل يشــل: الأهـداف، والمحتوى، والأنشـطة التعليميـة والتقويم بطريقـة تفاعليـة، وهـو الوثثيـة المرجعيـة الأساسية للمعلم فالاتجاهـات الحديثـة تؤكد على ضرورة أن يحتوي على مهارات البحث العلمي. وتهدف المناهج الدراسية القائمة على خصائص المعرفة إلى: تمكين الطلبة من إجراء أنشطة بحثية متتوعة في المدارس، وتمكينهم من إجراء أنشطة بحثية تقع ضمن الأنشطة التعليمية وتشجيع الطلبة على إبراز دورهم القيادي والريادي المستقبلي

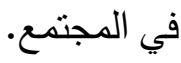

وتشبير الدراسـات السـابقة إلى: ضـعف التدريب العملي، وضـعف مهارات البحث المعرفي لدى الطلاب في جميع المراحل التعليمية(الزواوي، V · . Y)، وعدم .ह) . 


\section{المركن القومي للبحوث التبويةوالتنمية}

قدرة الطـلاب على توظيف منـاهج البحث العلمي وضـف توظيف أدوات المعرفة الحقيقية، والقدرة على النقد والتحليل والاستتناج، واتخاذ القرار وتوظيف المعلومات

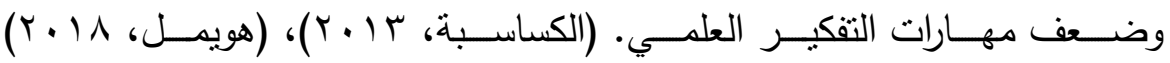
(Ambusaidi, 2000)، على الـرغم مـن أن البحـث العلمي أحـد المتطلبـات الأساسية للطلاب؛ لتكوين شخصية علمية تتسم بخصائص: التفكير الناقد، واتخاذ القرار ، والتتافسية العالمية (وزارة التربية والتعليم، 7 ( ـ ب)، أما بالنسبة لمناهج اللغة العربيـة فـلا نتــاول مهـارات البحـث العلمـي ولا تشـجعه لـدى الطـلاب، (اليـوبي،

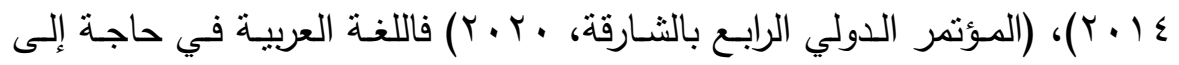
تضـمين معـارف ومهـارات المسـتقبل، فينبغـي أن تقوم على المخرجـات التعليميـة الآتية: تتمية عمليات التفكير- والقدرة على الإنتاج المعرفي، ...و أن تكون متكاملة تعبين علي إدراك التداخل والاندماج بين الحقول المعرفيـة، وتشـاعد الطـلاب على إدراك تكامـل المعرفـة، وتكـوين نظـرة شـاملة للظـواهر المختلفـة (شـحاته، م ... Y، ror) وكذلك حاجة مناهج اللغة العربية إلى مهارات التفكير المستقبلي أو مهارات القرن الحادي والعشرين ومنها: مهارات الحوار، والنقاش، والنقد، والتقكير والتحليل والربط، والاستتاج؛ ومن ثم فالمتعلمون ينبغي أن يمتلكوا هذه المهارات ليتعايشوا، ويتواصلوا مـع الآخرين، ويتمتعوا بقبولهم، ويواكبوا التطورات الحديثة، من خـلال الطرائق التفاعلية التي تركز على المهارات والممارسة والأداء. (عوض، 9 أبـ،

ويمكن تحديد مشكلة البحث في السؤال الرئيسي التالي: مـا مدى اشتتمال

مقررات اللغة العربية على خصائص المعرفة القائمة علي البحث العلمي؟ ويتقرع عنه الأسئلة الآتية: 


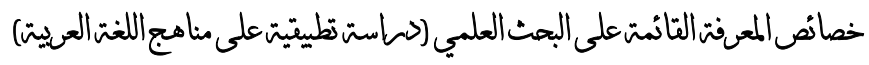

$$
\text { - ما البحث العلمي، وما أنواعه، وما خصائصه؟؟ }
$$

- مـا مــدى اثـتمال مقـررات اللغـة العربيـة للصـفوف الأول والســادس

الابتدائي والثالث الإعدادي والثالث الثانوي على خصـائص المعرفـة

القائمة على البحث العلمي؟

\section{أهمية البحث:}

$$
\text { ترجع أهمية البحث الحالي إلى أنه: }
$$

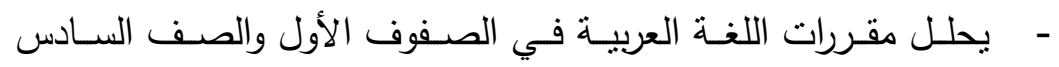

الابتدائي والثالث الإعدادي والثالث الثانوي في ضـوء مدى اشتمالها

على خصائص المعرفة القائمة على البحث العلمي.

- - يوجـه القائمين على إعداد مقررات اللغة العربية إلى تضمين المعرفة

القائمسة على البحث العلمي في أهدافها ومحتواهـا وأنشطتها وأسـاليب إعدانه

$$
\text { تقويمها. }
$$

- يوجـه أنظار الباحثين إلى إعداد بحوث عن البحث العلمي ومهاراته

وخصائص المعرفة القائمة عليه في اللغة العربية وفروعها وفنونها.

تحديد مـدى اثـتمال مقررات اللغـة العربيـة في الصـفوف الأول والسـادس

الابتدائي والثالث الإعدادي والثالث الثانوي على خصـائص المعرفـة القائمسة على

البحث العلمي. 


\section{المركن القومي للبحوث التبويةوالتنمية}

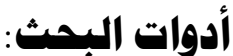

- استمارة تحليل محتوى مقرر اللغة العربية في ضوء خصائص المعرفة

القائمة على البحث العلمي.

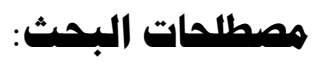

المهزفة:

المعرفـة هـي " مفهوم شـامل وعـام بكل مـا يحيط بالإنسـان مـن أحكام

وتصورات ومفاهيم ومعتقدات في مختلف مجالات النشاط الإنساني. " وهي " ذلك

الرصيد الهائل من العلوم والمعلومات التي اكتسبها الإنسان خلال مسيرته الطويلة

بحواسه وفكره وعقله." وينظر أيضا إلى المعرفة بأنَّها " شبكة مفهومية تتضمن كل

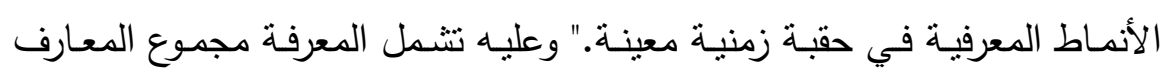

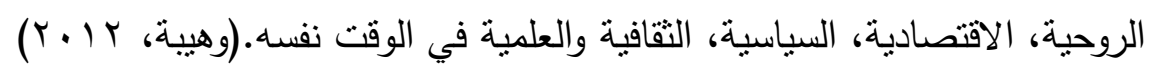

كما يحددها قاموس أوكسفورد بأنها المهارات المكتسبة من قبل شخص ما

مـن خـلال التجربـة أو التعلـيم والفهم النظـري أو العملـي لموضـوع مـا، والحقـائق

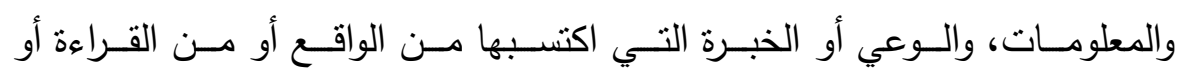

المناقنة.) (Oxford University)

والمَعرِفَة في البحث الحالي هي الإدراكَ والوعي وفهم الحقائق عن طريق العقل المجرد أو بطريقة اكتسـاب المعلومـات بـالإجراءات العمليـة وتفسير النتائج بأسلوب بحثي.

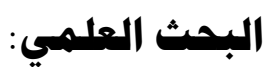

يتكون مصطلح "البحث العلمي" من كلمتين “البحث" و "العلمي"، يقصد

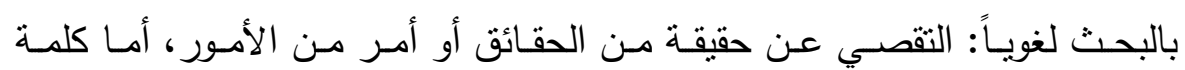


“العلمي” فهي كلمة تتسب إلى العلم، والعلم معناه المعرفة وإدراك الحقائق، والإحاطة والإلمام بالحقائق، وكل ما يتصل بها، ووفقاً لهذا التحليل، فإن “البحث العلمي" هو عملية تقصي منظمـة بإتباع أسـاليب ومناهج علمية محددة للحقائق العلمية بغرض التأكد من صحتها وتعديلها أو إضافة الجديد لها".

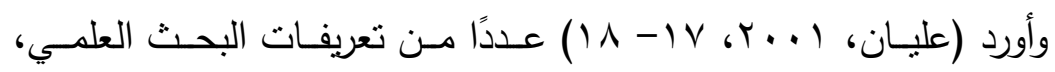
ومنها تعريف Whitney للبحث العلمي بأنه: استقصاءٌ دقيقُّ يهدف إلى اكتشـاف

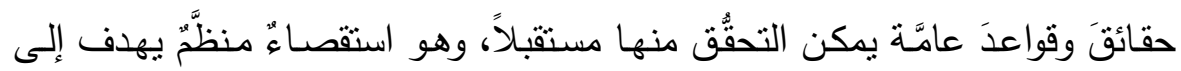
إضـافة معسارف يمكن توصـيلها والتحقُّق مـن صــتها باختبارهـا علميّاً، ويعـرف

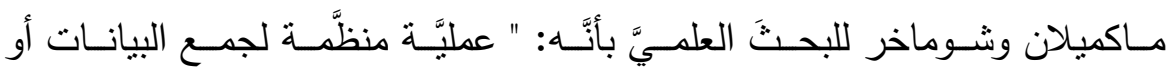

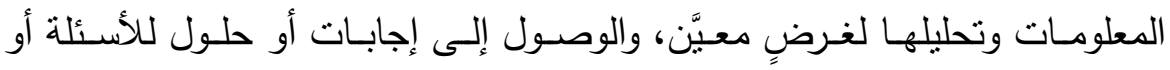
المشكلات التي تواجه الأفراد أو الجماعات في مواقعهم ومناحي حياتهم. والبحث العلمي نشـاط علمي منظم، وطريقة في التفكير واستقصـاء دقيق يهدف إلى اكتشاف الحقائق، معتمداً على مناهج موضوعية من أجل معرفة الترابط بين هذه الحقائق واستخلاص المبادئ العامـة والقوانين التفسيرية.(قاسم، r ا • ب)-

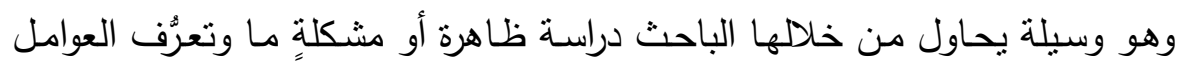
المؤثنّة في ظهورها أو في حدوثها للتوصُّل إلى نتائج تفسِّر ذللك، أو للوصول إلى هـ

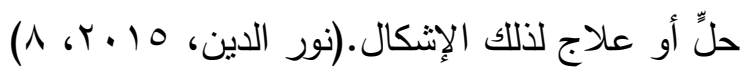

ويقصد بالبحث العلمي في البحث الحالي: المهارات التي تقوم على بناء شخصية الطلاب العلمية والتي ينبغي أن تشنمل عليها مقررات اللغة العربية. 


\section{المركن القومي للبحوث التبويةوالتنمية}

\section{خمائص المعرفة القائمة على البمث العلمي:}

إذا كانت المعرفة هي حصيلة الامتزاج بين المعلومـة والخبرة والمدركات

الحسية والقدرة على الحكم والمعلومات ووسيط لاكتساب المعرفة ضمن وسائل عديدة كالحدس والتخمين والممارسة الفعلية والحكم بالسليقة، ونستخدم كلمة المعرفة لتعني أننـا نمتلك بعض المعلومـات، وبذللك نكون قادرين على التعبير عنها. ومـع ذلك

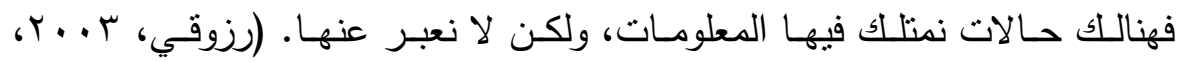

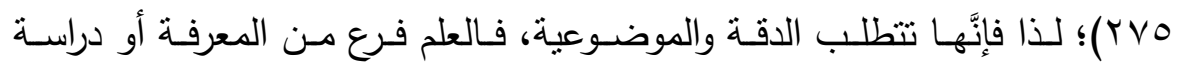
التعامـل مـع مجموعـة مـن الحقائق أو حقـائق مرتبـة بشـل منهجي وتبين تشـغيل القوانين العامة، والمعرفة المنهجية المكتسبة من الملاحظة والتجريب، وهو فرع من فروع العلوم الطبيعية أو الفيزيائية(Casey, 2012,5).و هو نوع من المعارف التي تتسم بالوحدة والتكامل والنسقية، كما يعتمد العلم على مبادئ تميزه عن باقي أنواع

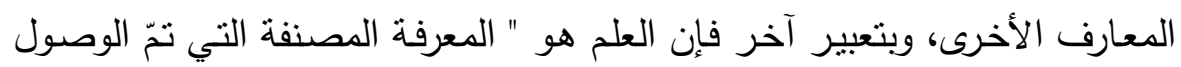
إليها بإتباع قواعد المنهج العلمي الصحيح مصاغة في قوانين عامـة للظواهر الفردية

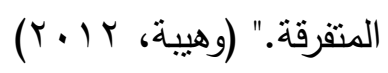

وعليه فالمعرفـة أثــمل وأوسـع مـن العلم، فـالعلم يقوم على دراسـة وتحليل الظواهر ، وهو جزء من المعرفة، بمعنى آخر فالمعرفة شاملة وعامـة تتضمن مختلف الجوانب الإنسـانية في شـتى المجـالات والتخصصـات، فـإذا اسـتطاع الإنسـان في مجال معين وتخصص دقيق أن يحدد ذلك المجال المعرفي بدقة ويقوم بالتجارب العلمية، ويصل إلى نتائج دقيقة فيما يتعلق بذلك الجانب المعرفي، ففي هذه الحالة

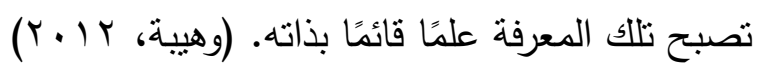


المعرفة القائمـة على البحث العلمي مجموعة من الخصـائص التي تتميز بهـا المعرفـة، وفي ذات الوقت نسـتـد إلـى البحـث العلمسي، وتقـوم عليـه مثتل: الموضوعية والدقة والتحقق والتفسير الموجز والإمبريقية والتفكير الاحتمالي. أما التعريف الإجرائي لخصائص المعرفة القائمة على البحث العلمي فهي: مجموعـة مـن الخصـائص المرتبطة بالمعرفة، وتميز هذه المعرفة عندما تكون معرفة علمية - حيث تُعَّد المعرفة أكثر شمولاً من العلم - وفي ذات الوقت مرتبطة وقائمة على البحث العلمي، الذى يتصف بعدد من الخصائص التي تعتمد عليها المعرفة العلميـة، وهذه الخصائص هي: الموضوعية والدقة والتحقق والإمبريقية والتفسير الموجز والتفكير الاحتمالي.

\section{إجراءات البحث:}

يسير البحث الحالي وفق الخطوات التالية:

- الاطـلاع على الدراسـات والبحسوث التي تتاولت خصـائص المعرفـة

والبحث العلمي، وأهمية تضمين خصائص المعرفة والبحث العلمي في

اللغة العربية.

- إعداد استمارة تحليل محتوى لخصـائص المعرفة القائمـة على البحث

العلمي.

- تحليل كتب اللغـة العربيـة للصفوف الأول والسـادس الابتدائي والثالث

الإعدادي والثالث الثانوي، والتأكد من صدق وثبات التحليل.

- رصد نتائج تحليل كتب اللغة العربية على عينة البحث من الكتب.

- - مقديم التوصيات والمقترحات. 


\section{المركن القومي للبحوث التبويةوالتنمية}

\section{الإطار النظري للبحث}

\section{خصائص المعرفة القائمة على البحث العلمي \\ في هناهج اللغة العربية}

اللغــة العربيـة لغـة علميـة، ثقوم على البحث العلمي والمعرفـة العلميـة في

البحث فيها كلغة من اللغات، كما أنها لغة تعليمية بحثية يقوم من خلالها الطلاب باكتشـاب المهـارات البحثيـة بممارسـة أنتـطة تعليميـة لغويــة ينبغـي أن تتضــنها مقرراتها في المراحل التعليميـة التي يدرسـها المتعلمـون. وبتتـاول الإطـار النظري للبحـث: خصـائص المعرفـة القائمسة على البحـث العلمسي، ومنــاهج اللغــة العربيـة والمعرفة القائمة على البحث العلمي.

\section{أولاً: خصائص المهرفة القائمة على على البحث العلمئ.}

تباينت الاتجاهات في تحديد أدوات المعرفة ومصادرها كالتالي:

- الاتجاه العقلي: ويرى أن الانسان يعتمد على عقله في الاستدلال ومعرفة ما يحيط به، وأنه القوة الفطرية التي تكسبه المعرفة التلقائية دون التعرض للتجارب. - الاتجاه التجريبي: فالتجربة أكبر برهان وأسلوب لاكتساب المعرفة. - الاتجاه الحسي: يرى العقل مجرد وهم وليس سبيلاً للمعرفة، وقدّم للعالم براهين حول أهمية الحدس في المعرفة والتي تقوم على التجربة الوجدانية. -الاتجاه البراجماتي: مجموعة المبادئ التي تشير إلى أن الفكر وسلامته هو ما يعدد إليه الانسان لاستخدامه للوصول إلى المعرفة، وبالتالي الحصول على نتائج ناجحة. (Britannica Encyclopedia, 2015) 
وتتــوع تصـنيفات المعرفـة ومنهـا: المعرفـة المسـتمدة مـن البحـوث الأوليـة، والمعرفـة المستمدة مـن المـنح الدراسـية والمراجعـة، والمعرفـة المتضــنة في المـواد والإجـراءات والمعرفـة الموجودة لـدى الممارسين والمعرفـة الموجـودة في المنـاهج الدراسية واختبار الفصـول الدراسية. والمعرفة الفنية (الهياكل التوضيحية أو نمـاذج

(المجال).) (Abell, S.K. 2007)

بينما صنَّفها كل من: Quintane وآخرون إلى: المعرفة المنظمة بشكل عام، كما في الحقائق أو المبادئ؛ والمعرفة المكتسبة من قبل دراسـة منهجية، والمعرفـة

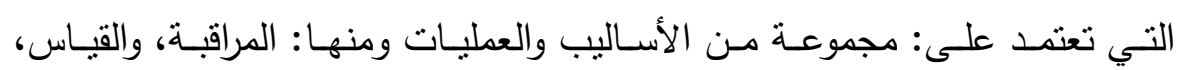
والتقدير ، والاستتناج، والمعرفة التي تعتمد على: الملاحظة والاستـدلال، وتتضـن هـذه الملاحظـة جــع المعلومـات باسـتخدام الحـواس الخمس، بينمــا الاســـلالات تفسيرات تسـتـد إلـى الملاحظـة التي تـؤدى للمعرفةـ (15-7) Casey, 2012,7)، والمعرفة الحسية التي يتحصل عليها الإنسـان عن طريق حواسـه، وهذا النوع من المعرفـة يقتصـر على مجـرد ملاحظـة بسـيطة تقف عند مسـتوى الإدرالك الحسـي العادي دون أن تتجه هذه المعرفة إلى إيجاد الصـات أو تسعى إلى إدرالك العلاقات

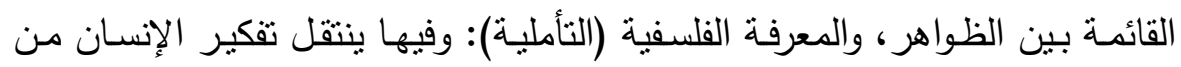
مرحلة الإحساس إلى التأمل في الأسباب البعيدة (ما وراء الطبيعـة) والموضـوعات المعقدة كالبحـث عـن المـوت والحيـاة، وصـفات الخـالق ووجـوده، وهذا النـوع مـن المعرفة يتحصل عليه الإنسان باستخدام فكره، حيث بستخدم أساليب التفكير والتأمل الفلسفي لمعرفة الأسباب والحتميات البعيدة للظواهر، ممـا بتعذر حسمه بالتجربـة.

$$
\text { (وهيبة، r (r) }
$$

وهناك من قسّم المعرفة إلى الأنواع الآتية:

EYT . 


\section{المركن القومي للبحوث التبويةوالتنمية}

- المعرفة المعيارية: وهي تحتوي ما ينبغي أن يحدث.

Quintane - المعرفة التنظيمية: تعرض المعرفة باعتبارها سلعة موضوعية -

(\&Casselman, 2011, 17)

- المعرفة العلمية: هي المعرفة المشتقة من البيانات والأدلة التي تم جمعها

عـن طريـق الملاحظـة والفرضـية والتجربـة والتوصـل إلـى تقسـير الظـاهرة

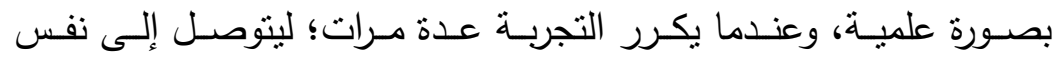
النتيجـة، فالمعرفـة في هذه الحالـة هي معرفـة علميـة، وتقوم أساسـا على

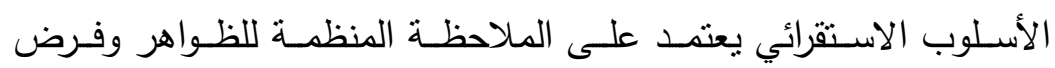

$$
\text { الفروض وإجراء التجارب (Casey, 2012,8). }
$$

وهنالك العديد من العوامل التي تؤثر على مدى نجاح مصدر المعرفة ونقل المعرفة إلى المتلقي. ومنها:

- الثقة والمصداقية: فإذا لم يكن المصدر ذا مصداقية، فسيكون من الصعب

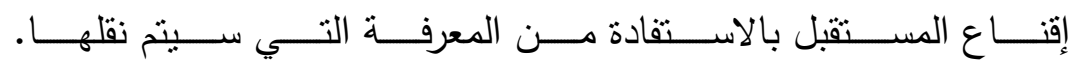
(Eppel ،p. 31) يقوم بتأدية دوره في إكساب الطـلاب المعارف والمعلومات ومهارات البحث العلمي بمهارة عالية. - الدافعية بين المستقيدين لاستيعاب المعرفة والاستفادة منها: فيؤثر على نقل المعرفة بنجاح بين الأطراف، فوجود دافعية بين مصدر المعرفة وبين متلقيها

يحقق الاستفادة الكاملة المرجوة منها - استيعاب المستقيدين: قدرة الطلاب على تفسيرها واستيعابها وتطبيق المعرفة الجديدة. 


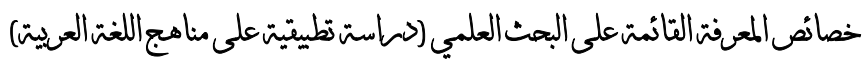

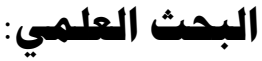

البحـث العلمـي يعنـى محاولـة اكتشـاف المعرفـة والتتقيب عنهـا ونتميتهـا

وفحصـها وتحقيقها بتقصـي دقيـق ونقد عميـق، ثمُ عرضـها عرضـاً مكنملاً بـذكاء وإدراك.(سكيك، (1) ( ب)، والطريق الوحيد للمعرفة حول العالم مرتبط بالعلم وطرقه المختلفة ، ويستخدم لتأكيد حقائق أو نتائج سابقة أو لحل مشكلات قائمة أو جديدة أو لدعم برهنة أو تطوير نظربة.

وهو أسلوب منظم في جمع المعلومات الموثقة وتدوين الملاحظات والتحليل الموضوعي لتلاك المعلومات باتباع أساليب ومفاهيم علمية بقصد تأكيدها أو تعديلها أو إضـافة الجديد لها، ومن ثم التوصل إلى نظريات جديدة أو برهنة أخرى والتتبؤ بحدوث ظواهر والتحكم في أسبابها. ومسن منـاهج البحـث العلمسي: المـنهج الاسـتنباطي، والمـنهج الاسـتقرائي، فالمنهج الاستتباطي هو انتقال الذهن من العام الى الخاص ويتولى رفع الغموض عن الموقف العلمي في أي واقعة من وقائع الحياة، وهو أحد عمليات الاستـلال العقلي الذي يستخدم في العلوم المختلفة؛ لذا فهو عملية استخلاص منطقي ينتقل فيه الباحث من المقدمات إلى النتيجة التي تكون متضدنة في المقدمة، وهذه الطريقة بطلق عليها الاستـلال، أمـا المنهج الاسـتقرائي: فهو عمليـة اسـتلال برتقي فيـه الباحث من الحالات الجزئية إلى الحكم العام، وينتقل إلى نتيجة غير متضمنة في

$$
\text { المقدمات (الهنداوي، } 7 \text { 1 • ب). }
$$

ويجب أن يُظهر البحث إمكانية للنجاح والتقدم المعرفي، وبالتالي تعزيز آفاق المستقبل الوظيفية للباحث ومبدأ الكتابة العلمية هو الصدق والثقة والأخلاق، وتجنب أي نـوع مـن أنـواع التصـنيع والتزويـر والانتحسال ومــا إلـى ذلـــ، فالكتابـة العلميـة .$\Sigma Y \wedge$. 


\section{المركن القومي للبحوث التبويةوالتنمية}

الصـادقة هي تحدي جدير يمـنح الباحث الطاقـة والثقـة والسـعة الطيبـة والنجـاح

الثخصي (Balakumar \& Jagadeesh, 2011)

ويمكن تصنيف البحث العلمي: بعدة طرق كالآتي:

وفقًا لتقنيات جمع البيانات: كالملاحظة، والتجريب.

- وفقًا للعلاقات السبيية: كالوصف، والتحليل.

وفقا للعلاقات مع الوقت: بأثز رجعي، الاحتمال، الاستعراض.

- وفقًا للوسيلة التي يتم تطبيقها من خلالها: المختبر، والبحوث الوصفية

Çaparlar, الاجتماعيـة. مثنل سلسـلة مـن الحـالات، دراسـات المراقبـة

$(2016,44)$

ومن متطلبات تحقيق الطريقة العلمية في البحث العلمي:

التكـرلإ:فإذا كان على الباحثين الآخرين إجـراء نفس الدراسـة، فيجب أن

يكونوا قادرين على الحصول على نتائج ممانلة، إن لم تكن متطابقة.

الاقةة:على الرغم من صعوبة التعميم النظري في كثير من الأحيان، يجب

بذل الجهود لتحديد هذه المفاهيم بدقة بطريقة تجعلها مفيدة للآخرين في

قياس منل هذه المفاهيم ونظريات الاختبار العلمي. القابلية للتغيير: يجبب

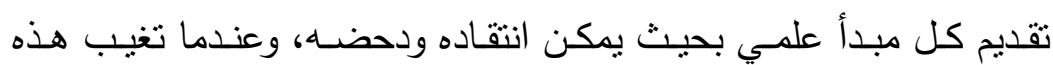

الميزة، فلا يمكن الإشارة إلى ذللك كنظرية علمية، وتكون المعرفة فيها غير

علمية.

- التحقق: النظريـات العلميـة، يتم اختبارهـا والتأكد من صـتها، حيث يتم

عـرض النظريـات في أثـكال شـاملة بـالتزامن مـع مفـاهيم يمكن قياسـها

واختبارها بدقة. ( Alakwe, 2017$)$ 
خصانص المعنتا التانتت على البجث العلمي (هاست تطيتيت على مناهج اللغتا العييت)

وتنتوع أهداف البحث العلمي وفقاً لنوعه وطبيعة النتيجة التي يتوصل إلبها، ومن

$$
\text { أهم أهداف البحث العلمي ما يلي: }
$$

الوصـول إلى حقائق جديدة: باستخدام التفكير المنهجي وتحليل الظواهر والمشكلات والسـعي لإيجاد حلول محققه لها، مـع الاستتاد على الحقائق الموثوقة، بما يتيح استتناج حقائق وتوصيات جديدة. - الوصف العلمي: من خلال تحليل ظاهرة ما، وتتبّع أساسها وتفنيد مسبباتها وتحليل أعراضها للوصول إلى الوصف العلمي الاقيق لها، باكتمال أجزاء البحث العلمي وتحليل المشكلة أو الفرضية ومكوناتها وتداعياتها الظـاهرة والمستترة والتوصل لوصف موضوعي يشمل التوجيهات للحلول الأمنل. - التبـؤ بالمستقبل: وهو تتبؤ مبني على الدليل العلمي والمنهجية الموثقة والخطوات المنطقية المتتالية، كل ذلك يكفل الوصول إلى معرفة مستقبلية أقرب ما تكون للحقيقة مع البحث العلمي الصحيح. - - تقديم حلول منطقية للمشكلات: يدور موضوع البحث العلمي حول مشكلة يلجأ الباحث لتفنيدها وحلها عن طريق البحث وطرح الفرضيات والملاحظة والقياس وغيرهـا، ويتمكن مـن طرح جملـة مـن الحلـول المدعمـة بالـلائل

$$
\text { وتكمن أهمية البحث العلمي في أنه: }
$$

- طريقة علمية منظمة في مواجهة المشكلات اليومية والعامة.

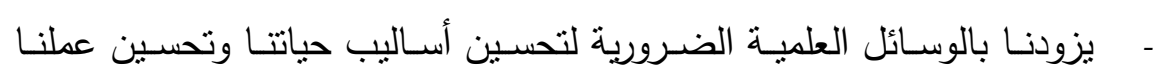
وتطوير أنفسنا.

$$
\text { . }
$$




\section{المركن القومي للبحوث التبويةوالتنمية}

\section{- برفع كفاءة الفرد لإنجاز عمل معين.}

- يحقق طموحات المجتمع المادية والتعليمية والثقافية.

- ــ يجلب الكثير من المنافع، وذلك لأن العلم والتكنولوجيا اللذين يرتبطان بالبحث العلمي، يمثلان ملكية عامة لكل الثـعوب والأفراد، وتقع على عاتق الباحثين مسؤوليات خاصـة في تحقيـق المنفعـة العالميـة من خـلال العمل على زيـادة المعرفة.

- يجمع النـاس معـاً مـن مختلف المنـاطق والأمـم والثقافـات في تفـاهم واحترام منبادل عن طريق البحوث التعاونية، فالمعرفة العلمية رصيد من الخبرة والفكر المشترك.

- يساعد على قبول أو رفض التغيير وآثاره البعيدة في المجتمعات. - ينمي الرغبة في مواجهة التحدي لحل المسائل العلمية. - يستخدم البحوث عن الثك في نتائج بحوث ودراسـات سابقة واكتشاف مدى جدية هذه الدراسات والأبحاث. - يساعد نتائج البحوث على إثقان العمل وزيادة كفاءته، وبالتالي زيادة الإنتاج

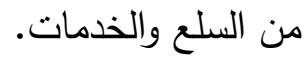
- ينمي حب الاستطلاع وتعرف الجديد واكتشاف المجهول.

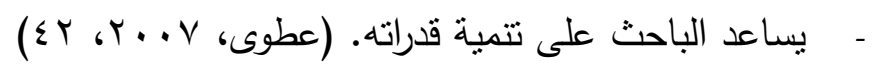




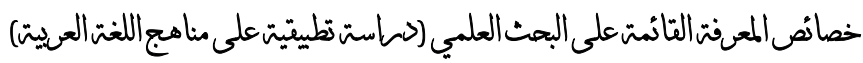

يجب على المعلمين بجميع تخصصـاتهم التمييز بين المعرفـة بالموضـوع

والمعرفة المهنية، وأن يتعمقا في المنهج العلمي، وأن يتعلم كل منهم إجراءات نوليد المعرفة والتحقق منها والمهارات المناسبة، والانغماس في قاعدة المعرفة العلمية. (Hegarty, 2001, 3)، ويحدث ربط فرص التعلم وزيادة مهارات البحث العلمي للطـلاب بشـكل أكثر وضـوحًا، عندما يكـون المعلمون ذوي معرفـة واسـعة وعميقـة بموضوع محدد والاهتمام بالدقة والتحقق في المعامل العلمية اللغويـة، وعلى وعي بالمفـاهيم البديلـة الثـائعة والنمـاذج العلميـة يمكـن أن تـوفر فرصًا تعليميـة ثريـة لطلابهم .(khourey \& Fenk, C., 2009)(Arzi, White, 2007, 91) ويلاحظ أن الباحثين والمؤلفين يقومون بإعداد الكتب المدرسية بعناية وفقًا للسياسات التحليمية المتعلقة بالمناهج الدراسية، ولكن عندما يتعلق الأمر بتتفيذها في الفصـول الدراسـية لا يتحقـق الهـدف مـن تطبيـق مـنهج معين لعدة أسـباب منهـا: معتقدات المعلمسين ومعرفتهم وكفـاءاتهم ووجهـات نظـرهم الخاصــة حـول المنـاهج الدراسـية، ولذا مـن الجدير أن يتمتـع المعلمـون بمعرفـة غنيـة ومرنــة بـالمواد التي يقومون بتدريسها... وفهم الحقائق والمفاهيم الأساسية للتخصص، وكيفية ارتباط هذه الأفكار والعمليات المستخدمة لإقامة معرفة جديدة (Borko, H. 2004, 33) حيث أثتتت الدراسـات أنَّ المعلمين الذين يعانون من ضـعف المحتوى المعرفى يفتقرون إلى التقـة لتنميـة مهارات التفكير العلمي لـى الطـلاب، لـا ينبغـي مـن ينبغـي أن shama تشنمل الكتب المدرسية على التعلم الاستكثـافي القائم على النشـاط. (Chunawala, 2011) ومن الأسـاليب التي يمكن أن يستخدمها المعلمون لتتمية البحث العلمي لدى الطلاب: معرفة محتوى المقررات الدراسية وكيفية تطوير تدريس هذا المحتوى من خـلا استراتيجيات جديدة وتطوير المحتوى المعرفي، واستخدام . ETY. 


\section{المركن القومي للبحوث التبويةوالتنمية}

خرائط وتسجيلات الفيديو للاروس والأدلة والأثشطة الإثرائية في الفصول الدراسية، وإجراء مناقثات ومحاورات مفتوحة مع الطلاب، وتدريب الطلاب على التعامل مـع الأدلة العلمية وعمليات الاستقصـاء، والتعلم بالممارسـة والتعلم عن طريق التفكير ، والتجـارب والعـروض العمليـة، وتوظيف المختبرات على اختلافهـا، ومهام التقبيم Ratcliffe and (Rollnick, 2017) (Heywood,D.S, 2007, 39)(العلمي) (Millar ,2009, 44)، واستخدام استراتيجية KWLH حيث كان لها تأثثر إيجابي في تطوير كل من أسـاليب التفكير الهيكلي والتحليلي والواقعي. ( Embarak, 2019)، وطريقة المشروعات إحدى الطرق الفعّالة في تنمية مهارات البحث العلمي فـي مهـارات (حـل المشـكلات - التفكيـر الناقـــ - الاتصــال) فـي مـادة اللغـة

$$
\text { الانجليزية. (القرالة، } 7 \text { الكب). }
$$

وتشير الدراسات إلى أن أعلى نسبة مهارات للبحث العلمي لمعلمي الطلبة

الموهوبين كانت في مهارة عرض البيانات، وأقل المهارات كانت لمهارتي تصميم البحـث وجمـع البيانـات وطرقها وأدواتهـا. (الزهرانـي، ع ا ـ ب) وأن درجـة امـتلاك معلمي اللغـة العربية والتربية الإسـلامية لمهارات البحث العلمي كانت منوسطة في مهارات: كتابـة البحث العلمي والمهارات الإجرائيسة في البحث العلمي، والمهارات العلمية في البحث العلمي والمهارات الثخصية، ومهارات نشر البحث العلمي.(عبود،

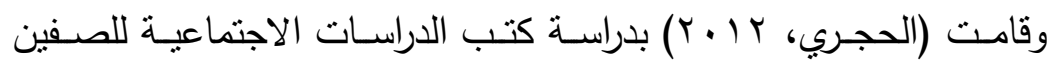
الحادي عشر والثاني عشر في سلطنة عمان وتوصل إلى أنها: قد احتوت على مهارات البحـث العلمي التاليـة: مهارات تحليـل البيانـات وتقسـيرها ومناقثـتها، ثم مهارات اختيـار المشكلة البحثيـة، ومهارة كتابـة تقريـر البحث، ومهـارات المنهجيـة . 


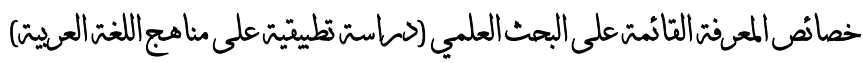

البحثيـة وإجراءاتها، ومهارات الخطـة البحتيـة، وأن هنالك حاجـة إلى التركيز على مهارات البحث العلمي المتعلقة بإعداد الخطة البحثيـة واختيـار المنهجيـة المناسبة، ومهارات صباغة العنوان وتحديد الهدف والمبررات وتحديد المنهاج المناسب، وبناء الأداة البحثية التي تحقق الغرض من الدراسة، خاصة كتب الصف الثاني عثر. وتوصلت دراسـة (الناقة والعامودي، 10 ـ ب) إلى أثر عملية إثراء الوحدة

التعليميـة بمضـامين الإعجـاز العلمي في القرآن الكريم في تتميـة مهارات التقكير العلمي، والمبادئ العلمية، واشتملت أدوات الدراسـة على: (اختبار لمهارات التفكير العلمي، واختبار للمبادئ العلمية، وقائمة بمهارات التفكير العلمي في مهارات: بناء النماذج، والتجريب والقياس، والتتبؤ، والاستتناج، والتصنيف، والملاحظة. وأظهرت نتائج دراسـة بعاره والقاعود والجوارنـة (9 ( • ب) أن كتاب التاريخ لطـلاب المرحلــة الأساسية العليـا للصف العاثـر تتسـم بالتدرج والتتابع المنطقي لمهارات ومعارف المصادر الأصلية، يليه كتاب الصف التاسع وفي المرتبة الأخيرة كتاب الصف الثامن، مما يؤكد وجود استراتيجية واضحة لدى مؤلفي كتب التاريخ تراعي التدرج في تضمين هذه المهارات البحثية، وبالتالي تدرج إكسابها للطلاب.

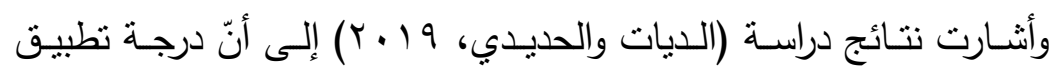
معلمي غرف المصادر لاستراتيجيات القراءة كانت مرتفعة، أمسا بالنسبة لاتجاهاتهم نحو البحث العلمي وممارساته فكانت سلبية، ودرجة تطبيق المعلمين لاستراتيجيات القراءة المستتدة على الأدلة العلمية واتجاهاتهم نحو البحث العلمي تختلف باختلاف مؤهلاتهم العلمية، وخضوعهم لأي شكل من أثكال التدريب. وقامت (Ajidah, 2017) بتحليل وتطوير الكتاب التعليمي على أسـاس المدخل العلمي، لتعليم اللغة العربية لطلاب الفصل الخامس من المدرسة الابتدائية 


\section{المركن القومي للبحوث التبويةوالتنمية}

الإسـامية، على نمـوذج ديلك وكـاري، بتحليـل الاحتياجـات والمشـكلات، وتصـميم الإنتاج، ثم تطوير الإنتاج، ثم التجربة وتقويم الإنتاج، وقامت الباحثة بالتطبيق على طلاب الصف الخامس الابتدائي، ومن خـلال التحكيم العلمي والبحني فقد حصل الكتاب التعليمي المطور على نسبة AV، ال I \% من خبير تصميم الوسائل، ونسبة

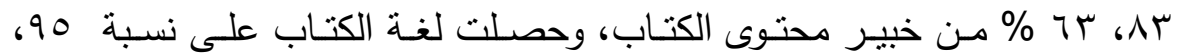
rr\% من خبير تصميم تعليم اللغة العربية، وكانت نسبة فعالية الكتاب التعليمي في

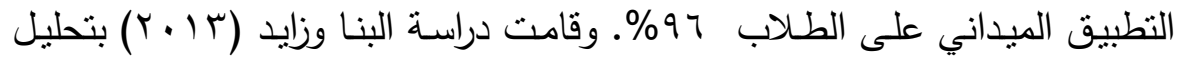
المضـامين الإبداعيـة "قيم الإبـداع" في مقررات التعليم الابتدائي، والتي تسهم في تشكيل الطفل المبدع، وتوصلت الدراسـة إلى أن قيمـة التفكير العلمي وتقدير العلم كانت أكثر قيم الإبداع تضمينًا في مقررات اللغة العربية (^, ؟r\%) يليها قيمة حرية

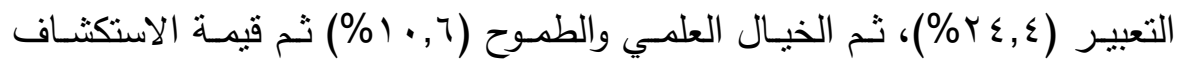

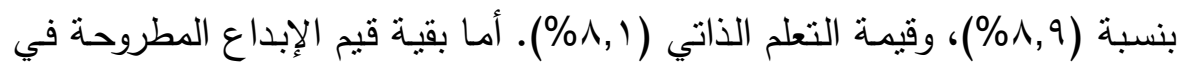
الدراسـة فجاءت متدنية، وخاصـة قيم الاستقلالية، والتجديد، واحترام الوقت، والحوار الحضاري.

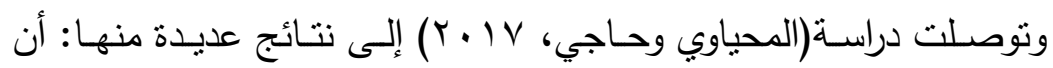

أنشــة كتـاب اللغــة العربيـة للصـف الأول الثـانوي راعـت مهـارة الطلاقـة بدرجـة متوسطة بلغت نسبتها ( • (\%)، بينما رُوعيت مهارة المرونـة بدرجة ضـعيفة بلغت نسـبتها (9 (\%))، في حين بلغـت نسـبة مراعـاة مهـارة الأصـالة(9,0 \%\%)بدرجـة متوسطة. ونسبة مراعاة مهارة التفاصيل (1,0 1\% ب بدرجة ضعيفة. وخرجت الدراسة بعدة توصيات من أبرزها: نوجيه نظر القائمين على تخطيط وتأليف مناهج اللغة 


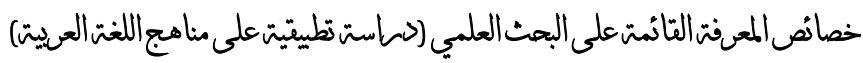

العربية إلى مراعاة التعريفات الإجرائية التي تعكس طبيعة مهارة الأصسالة بصورتها

الدقيقة.

كما أظهرت نتائج دراسـة (البري، ب ا ـ ץ) أن كتاب لغتتا العربية للصف

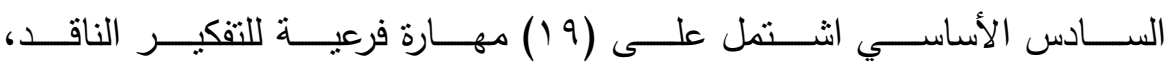
وقد نكررت (سTM) مرة، موزعة على خمس مهارات رئيسة هي: مهارة التعرف على الافتراضات، ومهارة التقسير، ومهارة الاستتناج، ومهارة التحليل، ومهارة التقويم. وحلّ (الضبة، با ـ ب) كتب اللغة العربية في ضوء مهارات التفكير فوق المعرفي للمرحلة الأساسية الدنيا، وقد أسفرت النتائج عن: احتواء كتب اللغة العربية للصفوف الثثلاثة (الأول-الثاني -الثالث) على المهارات الفرعية الثناث لمهارات مـاء وراء المعرفة (المهارة المفاهيمية- المهارة السياقية- المهارة الإجرائية)، حيث تقاوت توزيع هذه المهارات على أسئلة الكتب الثلاثة بشكل غير متوازن، كما افتقرت كتب اللغـة العربيـة لكثير مـن المهارات الفرعيـة الفرديـة للمهـارات التثلاث التي تعتبر ضرورية لبناء الثخصية المتكاملة القادرة على مواجهة الحياة ومشكلاتها. و البحث العلمي اللغوي يتضمن الكثير من المهارات البحثية مثل: البحث في المعـاجم والقواميس اللغويـة، وتقصسي دلالات الألفـاظ المختلفـة، والبحـث في الانترنت في المجال اللغوي عبر الرحلات المعرفيـة، والاستنتاج اللغوي والتحليل المنطقي، وكتابة تقرير علمي حول موضوعات لغوية. وربط اللغة العربية بالمعرفة والبحث العلمي يؤدي إلى: تكوين نواة للتتمية المؤسسـية القائمـة على اللغــة العربيـة وعلى المعرفـة، والبحـث العلىـي والإنتـاج والإبداع له أثز بالغ في تقوية مكانة اللغة عند أهلها، والإنتاج الاقتصادي المعرفي وتقاعل العلم اللغـوي والبحث في التتميـة الاجتماعيـة والاقتصـادية، والتأكيد على لـى . $2 \pi 7$. 


\section{المركن القومي للبحوث التبويةوالتنمية}

أهميـة اللغــة العربيـة فـي تطــوير الـوطن العربـي والحفـاظ علـى أمنــه اللغـوي

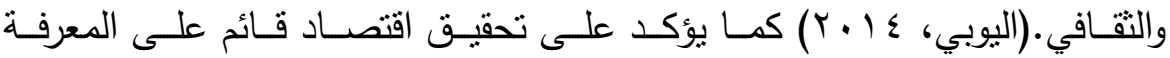
والصـناعة اللغوبـة، ودعـم مشـروع النهـوض باللغـة العربيـة للتوجّهـهـ نحـو مجتمـع المعرفـة، ودعــم بحـوث العلمــاء والبـاحثين ودراسـاتهم ومشــاريعهم، والتطبيقـات الحاسـوبية ذات الجـودة العاليـة في اللغـة العربية،، وإثراء المحتوى الرقمي العربي بمصـادر ومراجـع علميـة حديثـة باللغـة العربيـة (المنظمـة العربيـة للتربيـة والثقافـة

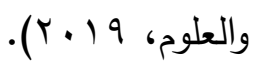

ومن المهارات التي ينبغي أن تشنمل عليها مقررات اللغة العربية في ضوء

$$
\text { خصائص المعرفة القائمة على البحث العلمي): }
$$

- الموضـوعية:وتتنتمل على: التمسك بـالروح العلميـة والتطلع دائمًا إلى معرفة الحقيقة فقط، والابتعاد قدر الإمكان عن التزمت والتشبث بالروئة الأحادية المتعلقة بالنتائج، والاعتراف بالحقيقة. (قاسـ، Y ( • Y)، كما تتضـمن: موضـوعية المنتج والموضوعية العملية، وعرض حقائق العلم بطريقة علميـة مجردة، وينطلق من: النظريات والقوانين والنتائج التجريبية والملاحظات - تمثيلًا دقيقًا للعالم الخارجي، ولا تتبع الرغبات أو الأهداف أو القدرات أو الخبرة والالتزام بالعمليات والأسـاليب التي تميزه معتمدة على القيم الاجتماعية والأخلاقية، وعدم التحيز الفردي والغياب الكامـل والمطلـق لذاتيـة الفـرد (مزاجـه، ثوقافتهـ، وإيديولوجيتهـه وأحكامـهـ المسـبقة واستتناجاته) في عمله العلمي، أي في جميع مراحل وخطوات البحث العلمي، سواء فيما يتعلق ببناء الموضوع وصياغة الإثكالية أو عند بناء الفروض العلمية، وذلك حتى يصل المتعلم الباحث إلى حكم علمي دقيق يمكن تعميمـه، كمـا أنَّ 
العلم يستخدم الأدلـة العقلية والبراهين المنطقيـة المستقلة عن العوامل الثخصية والذاتية."

الاقة:تعتبر من أهم الدعائم التي يقوم عليها الفكر العلمي، حيث تتميز المعرفة

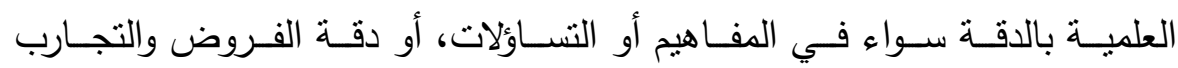
والاستتناجات والتعميمـات. وبعد جمع البيانـات، يـتم تحليلهـا، وغالبَّا مـا تسـتخدم الإحصائيات والحسابات، وينت استخلاص النتائج، كما تجعل البحث العلمي ذا قيمة وأهمية كبيرة، ويتأكد ذلك عندما ننظر إلى الأنظمة المختلفة، التي تمثل مجموعات من الأجزاء المترابطة العلوم.(wood, 2008)

التحقق: من خلال تبادل البيانات وإنتاج المعرفة التي تكون مشنقة من الدمج أو Towne \& Wise and المقارنـة أو الجمـع أو إعـادة التحليـل أو التكامـل (Winters, 2004,39)، والحصول على المعرفة، والدراسـة من خلال الملاحظة، ودراسـة الإجراءات وردود الفعل التي تحدث في حياة الإنسان واكتشـاف الحقيقة؛ بناءً على الحقائق والمعرفة المنهجية حول الأشياء الفيزيائية والكيميائية والبيولوجية مـن حولنـا، والفهم مـن خـلال الأسباب بعمق، ومـن خـلال المنطق ـ والدراسـة مـن

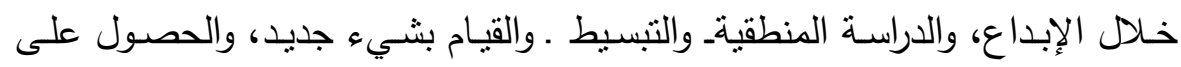
معرفة جديدة. (shama \&chunawala, 2011) -التفسير المـوحز:بـإدارج بعض أدبيات البحث التربوي في مقررات اللغـة العربية مثل: مفهوم الفرضيات ودورها في البحث العلمي، وخاصـة بعض معايير الفرضية

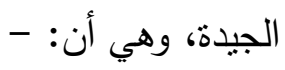
- تبنى الفرضية بشكل مباشر على البيانات. - تفسر البيانات الموجودة بطريقة أبسط من الفرضيات المناقثنة. .$\Sigma \Gamma \wedge$. 


\section{المركن القومي للبحوث التبويةوالتنمية}

- يُعبَّر عنها بشكل بسيط ومختصر .

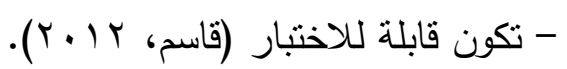

فتحقيـق خصـائص المعرفـة في مقررات اللغـة العربيـة "تتطلب عمليـات:

البحث، وتوفير الخبرات العلميـة "الحقيقيـة" التي تُمَكَّن الطـلاب مـن بنـاء معرفتهم الخاصـة بطبيعـة العلم والمعرفـة العلميـة، والتـي تتطلب مـن الطـلاب التفكير في في معارفهم الجديدة وعلاقة هذه المعرفة الجديدة بالطلاب في الصفوف الابتدائية. -الامبريقيـة: (الاعتمـاد على القواعد العلمبـة):بتبني الأسلوب العلمي في البحث من خلال احترام جميع القواعد العلمية المطلوبة للدراسة، وعدم تجاهل أو إغفال أي عنصر من عناصر البحث العلمي، وتقوم الامبيريقية على الاستقراء أو الاستتباط، والاستقراء العلمي استـلال مستمد من ملاحظـة وقائع خاصـة، بهدف استخلاص افتراضـات عامـة، فالمعرفة العلمية ناشئة عن ملاحظة الواقع، فهي تمنح الأسبقية لجمـع الملاحظـات عـن الظـواهر ، بهـدف الاسـتنتاج الممكن للافتراضـات العامةــ والاستتباط العلمي استـلال مستمد من افتراضـات عامـة بغيـة التحقق من صحتها في الواقع، فالعلاقات الممكنة بين الظواهر بنـاءات فكريـة يُمْكن التحقق منها في

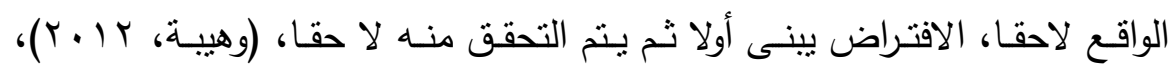
فالاستقراء والاستتباط يقومان بأدوار متكاملة وأساسية في الممارسة العلمية.

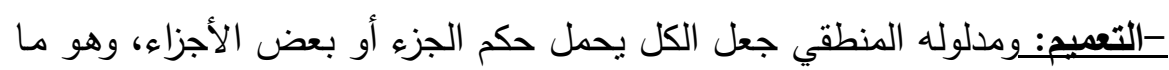
يُعْرف بعملية الاستقراء الناقص الذي يقوم عليه البحث العلمي، حيث يكتقي الباحث بدراسة بعض الحالات، ثم يقوم بتعميم الحقائق التي وصل إليها على الحالات التي لم تُدُرس، في حين يقوم الباحث في الاستقراء التام بملاحظة جميع مفردات الظاهرة 


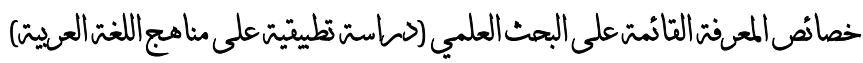

التي يقوم ببحثها، ويكون حكمسه مجرد تلخيص للأحكام التي يصدرها على كل مفردة من مفردات البحث. - التفكيـر الاحتمـالي:مجـالات التفكير الاحتمـالي جوهريـة ومهمـة للطالب الذي مني يحاول التفكير في سياق احتمالي وهي:

- الفضـاع العينـي: قائمـة المخرجـات الممكنـة لتجربـة عشوائية ذات مرحلـة

$$
\text { واحدة أو مرحلتين. }
$$

- الاحتمالبـة التجريبية لحدث مـا: بقوم على أساس إجراء التجربة العشوائية عدداً كبيراً من المرات، ويتحدد الاحتمال التجريبي بـالتكرار النسبي، وهو إهواء عدد مرات ظهور الحادث لتجربـة عشوائية أجريت عدداً من المرات إلى عدد مرات إجراء التجربة.

- الاحتمالبـة النظريـة لحسادث مـا: هو الحادث الذي بمكن قيـاس احتمالـه بطريقة حسابية، ودون الحاجة لإجراء تجارب، وتختلف الاحتمالات النظرية عن الاحتمالات التجريبية، في أن الاحتمالات التجريبية عرضة للتغير من وقت لآخـر ومـن مكسان لآخـر، أمسا الاحتمـالات النظريـة فهي لا تتغيـر إطلاقاً.

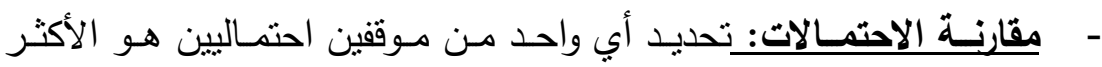
فرصسةً لتوليد حادث معين، أو فيمـا إذا كانـا يمتلكان نفس الفرصـة لتوليد الحادث المطلوب. - الاحتمال المشروط:ويتضمن فيما إذا كان احتمال حادث ما يتغير بحدوث

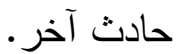




\section{المركن القومي للبحوث التبويةوالتنمية}

- الحوادث المستقلة: إدرالك وقوع حادث لا يتأثر بوقوع أو عدم وقوع حوادث

$$
\begin{aligned}
& \text { أخرى. }
\end{aligned}
$$

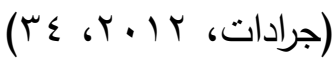

من خلال الإطار النظري للبحث تم الخروج بالأسس الآتية: - اللغة العربية لغة علمية تستوعب البحث العلمي ومهاراته تعليماً وإكساباً لمهاراته للتلاميذ في المراحل التعليمية المختلفة، خاصة في المرحلة الابتدائية، حيث يتم بناء شخصية المتعلم على إجراء البحث العلمي من خلال المحتوى اللغوي على اختلافه: قراعةً أو نحواً أو نصوص تعليمية يدرسها التلاميذ. - يرتبط تنمية مهارات البحث العلمي في مقررات اللغة العربية بقدرة معلمي اللغة العربية على تحليل المحتوى واستتناج مهارات البحث العلمي التي يمكن نتميتها، وتقديم أنشطة منتوعة في ضوئها.

- تحليل مقررات اللغة العربية من خـلال مدى اثتمالها على المعرفة القائمسة على البحـث العلمـي: (الموضـوعية، والدقـة، والتحقـق والتقسير المـوجز ، والإمبريقيـة، والتعميم، والتفكير الاحتمـالي) يكثـف مدى مسـايرة اللغـة العربيـة لمتغيـرات القرن الواحد والعشرين، وأنها مُنطورة مع المستحدثات العلمية. - تحليل مقررات اللغة العربية لاستكثاف مدى احتوائها على البحث العلمي، يتجلى

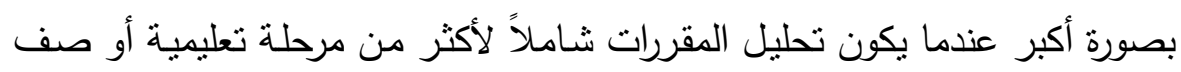
دراسي.

\section{الجانب التطبيقي للبشث دراث}

يقوم الجانب التطبيقي للبحث على تحليل كتب اللغة العربية عينة البحث في ضوء مدى اشتمالها على خصائص المعرفة القائمة على البحث العلمي. 


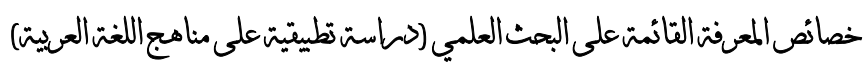

$$
\text { ويهدف تحليل كتب اللغة العربية إلى: }
$$

•تعرف مدى اشتمال كتب اللغة العربية على خصـائص المعرفة القائمة على البحث العلمي، ونتائج التكرارات والنسب والترتيب، وما تدل عليه. • تعـرف الأنماط المختلفـة التي استخدمتها الكتب المدرسية في تقديم الموضوعات من عناوين الدروس ومحتواها.

• تعرف الوسائل التي استخدنها هذه الكتب في ثقديم العناوين والدروس بما يدل على البحث العلمي من مصطلحات أو صور فوتوغرافيـة أو

$$
\text { وسوم كاربكاتيرية. }
$$

المضـمون الحقيقي للموضـوعات التي تقدمها كتب اللغــة العربيـة، ومدى اهتمامها بالبحث العلمي.

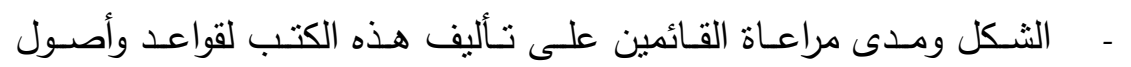

$$
\text { الإخراج الفني لهذه الكتب. }
$$$$
\text { وسار تحليل كتب اللغة العربية كالتالي: }
$$

- تحديد كتب اللغة العربية التي تمّ تحليلها. - تحديا وحدات التحليل وفئاته. - - إجراء عملية التحليل. - - رصد النتائج. - - التحليل الإحصائي للتتائج واستخراج المؤثشرات الخاصة بالتحليل. وفيما يلي تفاصيل التحليل:

\section{• تهديد كتب اللغة العربية التي تمّ تهليلها.} .$\Sigma \varepsilon Y$. البحث التربيوي 


\section{المركن القومي للبحوث التبويةوالتنمية}

تمّ تحديد خصـائص المعرفـة القائمسة على البحث العلمي؛ لتكون المعيار الـرئيس في كل عمليـات تحليـل المضـمون وهذه الخصـائص هـي: الموضـوعية، والدقة، والتحقق، التفكير الموجز ، والامبيريقية، والتفكير الاحتمالي.

ومقررات اللغة العربية من الاتسـاع والتتوع بما لا يمكن القيام بتحليل كل

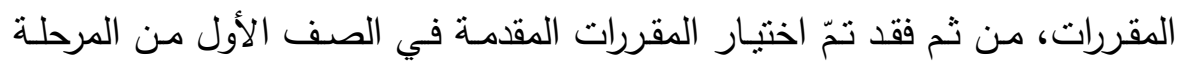

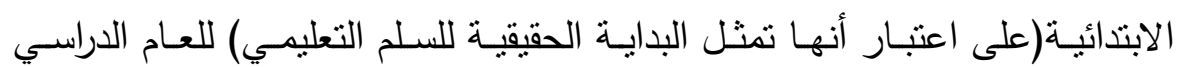

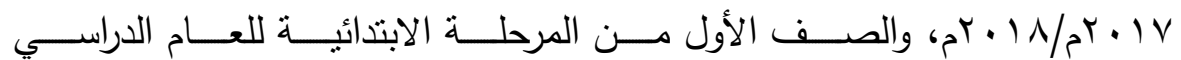

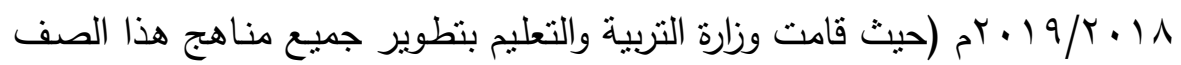
في هذا العام)، ثم نهاية المراحل الابتدائية والإعدادية والثانويـة (تمثل نهاية المراحل

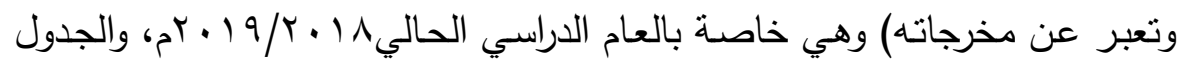
التالي يوضـح الكتب التي تمّ تحليلها.

جدول (1)

كتب اللغة العربية التي تمّ تحليلها

\begin{tabular}{|c|c|c|}
\hline السنة الدراسية & الكتاب المدرسي & الصف الدراسي \\
\hline$\cdot r^{r} \cdot 11 / r \cdot 1 V$ & 1 - اللغة العربية (هيا نقرأ). & \multirow{3}{*}{ الابتدائي } \\
\hline \multirow[b]{2}{*}{$r^{r \cdot 19 / r \cdot 11}$} & r- اللغة العربية (تواصل) & \\
\hline & 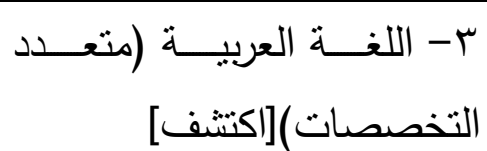 & \\
\hline$\beta^{r \cdot 19 / r \cdot 11}$ & ع- كتاب اللغة العربية & 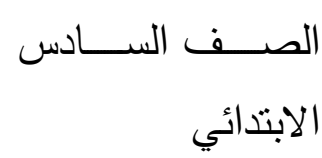 \\
\hline $2 r \cdot 19 / r \cdot 11$ & 0- كتاب اللغة العربية & الصـــــــ الثالــــــث \\
\hline
\end{tabular}




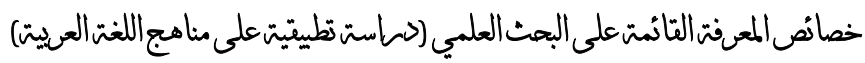

\begin{tabular}{||r|r|r|}
\cline { 2 - 2 } & & \\
\hline & & \\
\hline & & \\
\hline
\end{tabular}

\section{تهديد وحدات التحليل وفنئاته.}

يحـد البـاحثون وحـدات تحليـل المضـمون في: الكلمـة والموضـوع، والفكرة، والثخصـية، والوحـدة الطبيعيـة للمـادة التعليميـة، ومقـاييس المسـاحة والـزمن، وتـمّ اسـتخدام وحدة الكلمـة والموضـوع والفكرة فـي البحـث الحـالي؛ لأن وحـدة تحليـل الموضوع والفكرة من أنسب وحدات التحليل؛ لأنها تعتمد على الجملة أو الفكرة التي تدور حول قضية محددة، ونعني بها هنا البحث العلمي، ويمكن تقسيم الفكرة إلى العناصر التالية: - n

- الموضوع الذى تركز عليه. -الجوانب التي تتناولها. - القيم المتضمنة فيها. -الطريقة أو الأسلوب المتبع في عرضها.

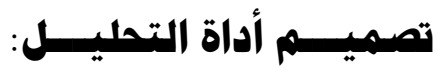

تم إعداد استمارة تحليل المضـمون، وحددت فئات الموضـوعات بها من خلال الأدبيات والدراسات التي ثََّّ تتاولها، والاطلاع عليها وأيضاً كتب اللغة العربية التي تَمَّ تحليلها من خلال: 


\section{المركن القومي للبحوث التبويةوالتنمية}

- تحديـد أهـم الموضـوعات ومعـايير ومؤشـرات تَبَيَّن مـدى احتوائهـا على مهارات البحث العلمي التي تتاولتها هذه الكتب، حتى إن كانت الأفكار التي يتم عرضها قليلة، فالمهم هو أنها تتاولتها.

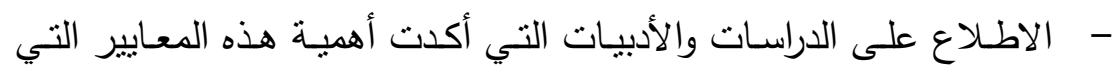
تتاولتها الكتب.

\section{فئُسـات التحليــل}

بالنسبة لتحديد الفئات التي تمَ على أساسها جمع المعلومات، فقد تم ذلك بعد

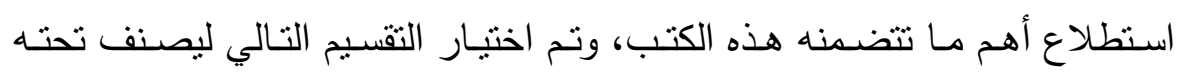
مضمون هذه الكتب:

فئات المضمون: ماذا قيل؟ وهى مرتبطة أكثر بموضوعات الاتصـال، ولكن

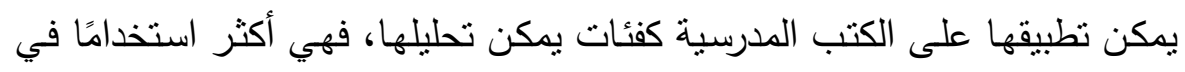
دراسات تحليل المضمون.

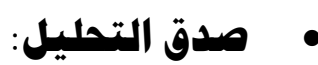

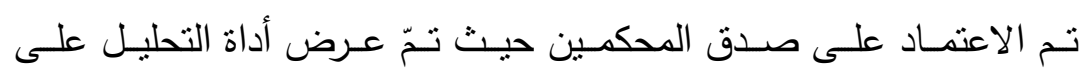
مجموعة من المتخصصين في طرق تدريس اللغة العربية لإبداء الرأي في: التوافق بين عناصـر المحتوى في التحليل، والالتزام بالتعريفات التي تم تحديدها لعناصـر

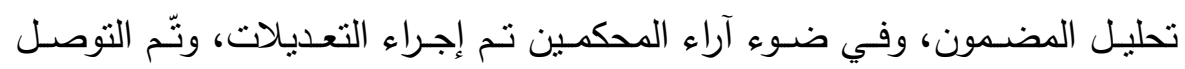
للصورة النهائية لتحليل محتوى الكتب عينة البحث. 


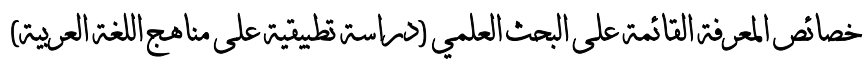

تم تحليل الكتب عينة البحث بفاصل زمنى بين التحليل الأول والثاني تراوح بين شهر إلى شهرين، وفيما يلي معامل الاتفاق بين التحليلين لكل كتاب من الكتب:

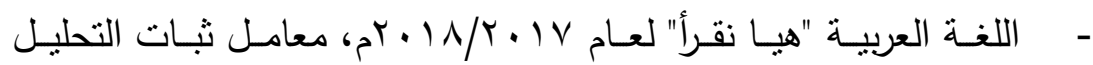

$$
.(\% \wedge v)
$$

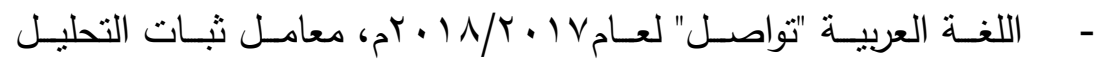

$$
\cdot(\% \wedge \varepsilon)
$$

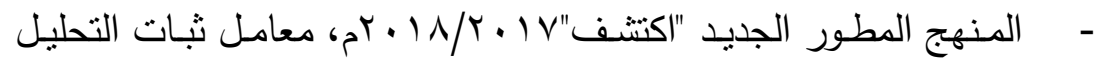

$$
.(\% \wedge r)
$$

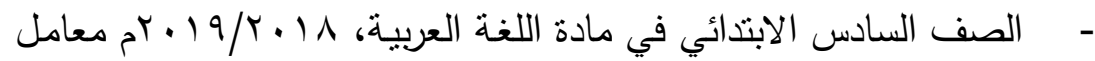

$$
\text { ثبات التحليل (T/ \% \%). }
$$

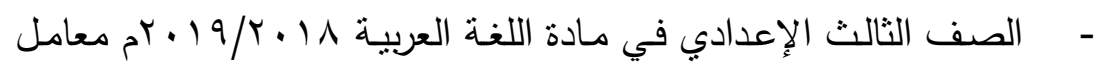

$$
\text { ثبات التحليل (10/\%). }
$$

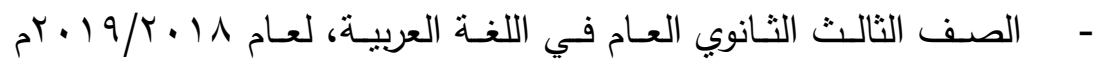
معامل ثبات التحليل (ء^\%). وتمّ تقسيم فئات الكتب المدرسية الرئيسة والفرعية إلى ما يلى:

$$
\text { أولاً: عناوين الكتب. }
$$

ثانياً: المقدمة التي تحتوى عليها الكتب.

$$
\text { ثالثاً: عناوين الدروس. }
$$$$
\text { رابعاً: أهداف الدروس. }
$$

خامساً: محتوى الدروس.

وفيما يلي الكتب الدراسية التي تََّّ تحليلها: 


\title{
المركن القومي للبحوث التبويةوالتنمية
}

\section{أولاً: مرحلة التعليم الابتدائي(الصف الأول الابتدائي)}

\author{
جدول (r)
}

يوضح خصائص المعرفة القائمة على البحث العلمي في مادة اللغة العربية" هيا نقرأ"

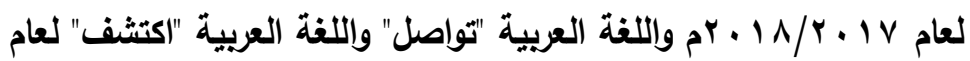

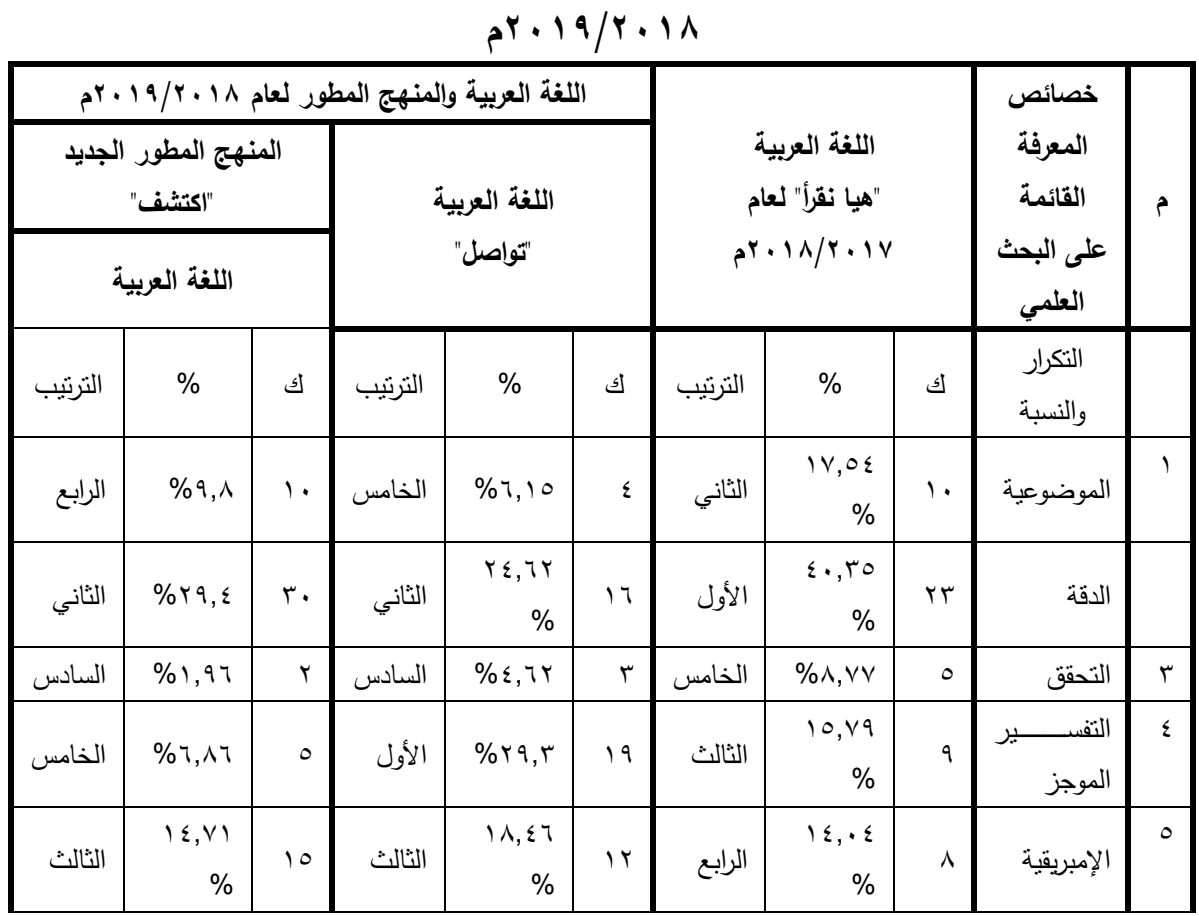
$. \varepsilon \leqslant V$. 


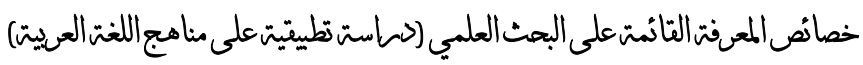

\begin{tabular}{|c|c|c|c|c|c|c|c|c|c|c|}
\hline الأول & $\begin{array}{r}r v, r_{0} \\
\%\end{array}$ & rA & الرابع & $\begin{array}{r}17,94 \\
\%\end{array}$ & 11 & السادس & $\% r, 01$ & r & الاحتمالي & 7 \\
\hline & $\% 1 .$. & 10 & & $\% 1 \ldots$ & 70 & & $\% 1 \ldots$ & ov & & مج \\
\hline
\end{tabular}

يتضح من الجدول السابق ما يلى:

أولاً: خصائص المهرفة القائمة على البحث الملهي في الاغة العربيسة

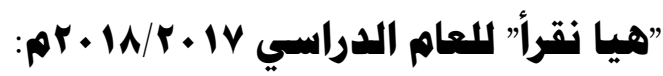

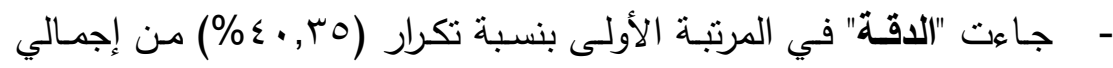

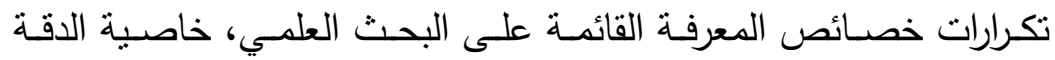
المرتبطة بالبحث العلمي ولم تتعد الثكل الظاهري فقط.

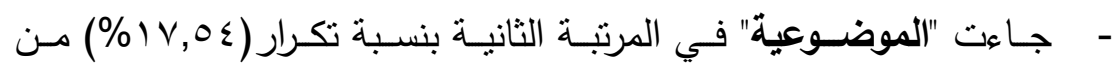
إجمالي التكرارات، وبرز ذلك بشكل واضتح في الوحدة الثانية، عندما تمَّم استعراض عائلة الحروف، وظهر الاتفاق على الأحكام الخاصـة بها، بينما

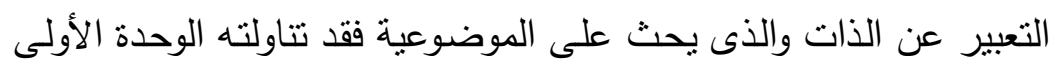
بشكل قليل نسبياً.

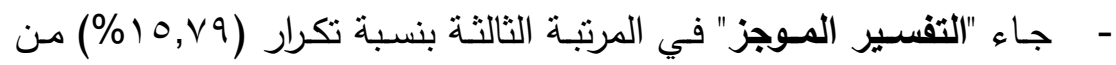
إجمالي التكرارات، وبرز في وضـع الصور الفوتوغرافيـة والكاربكاتيربـة في الوحدة الأولى، وفي الوحدة الثانية عند استعراض حروف الهجاء. 


\section{المركن القومي للبحوث التبويةوالتنمية}

- جاءت "الإمبريقية" في المرتبة الرابعة بنسبة تكرار (ع +, ـ (\%) من إجمالي

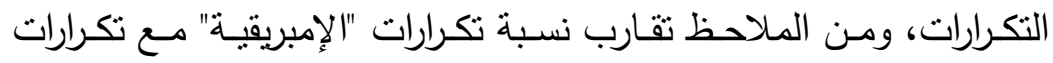
"التفسير الموجز"؛ حيث كانت الصور المفسرة تعبر عن الإمبريقية، وعلى الرغم من ذلك لم تعمل على تتمية خصائص البحث العلمي؛ لأنها ليست إجراءات منظمـة تعبر عن إمبريقية حقيقية. كما أنَّ عنوان الوحدة "التهيئة اللغويـة" بينما جـاءت الصـورة الظـاهرة للتلاميذ وهم يحيون العلم؛ ممـا قد يعمل على الازدواجية لهؤلاء التلاميذ الصغار .

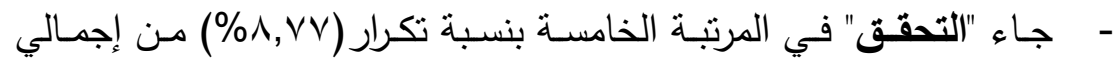
التكرارات، فالأهداف تم عرضها في أول كل وحدة دون التأكد من تحققها.

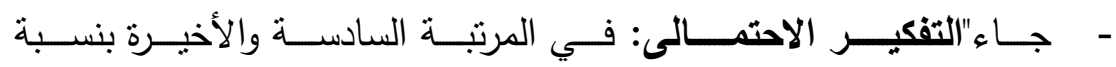

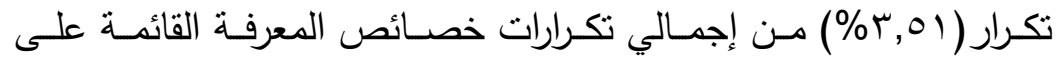

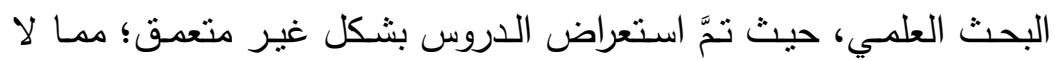
يدع مجالاً للتفكير الاحتمـالي، ومن المفترض إعطاء مساحة للنلميذ في هذه السـن الصـيرة للتفكير الاحتمـالي؛ حتى لا يتعـودوا على الهامشـية الهـية والسطحية بشكل مستمر - ون

ثانيا: خصائص المعرفة القائمهـة على البهـث العلمـي في اللغـة العربيسة

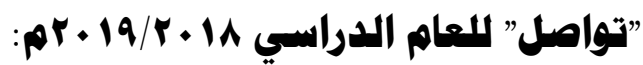

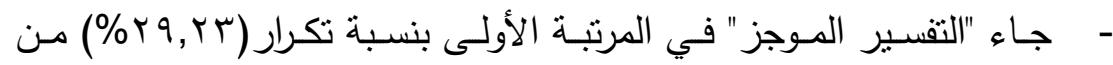
إجمـالي تكـرارات خصـائص المعرفـة القائمـة على البحـث العلمي، وكـان

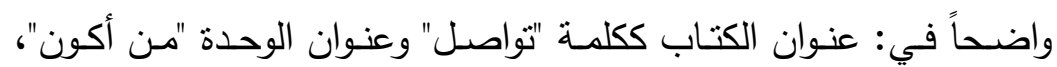
وكان من المفترض الاهتمام بشكل أكبر بعملية التقسير بشكل عام، وليس الموجز ؛ نظراً لصغر سن التلاميذ في هذه المرحلة. 
- التكرارات، حيـث تمّ الاهتمـام بمراعـاة الدقـة في توصسيل معلومـة محسدة للتناميذ في تعليمهم القراءة والكتابـة، وقد اعتمدت الأنشطة في الدروس الدماه

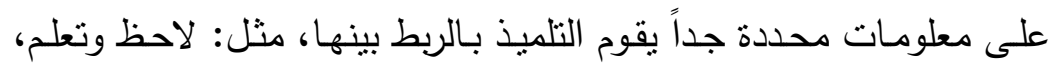
التي يستعرضها الكتاب في كل جزئية تالية للارس الرئيسي.

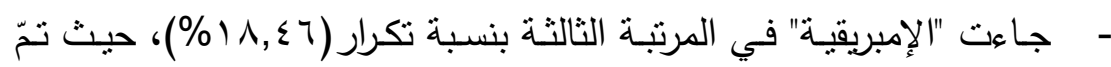
الاهنمام بالثواهد والأدلة في الدروس.

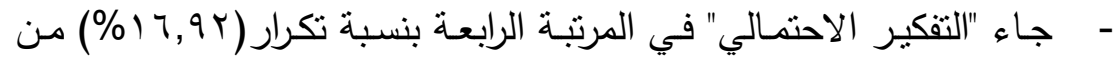

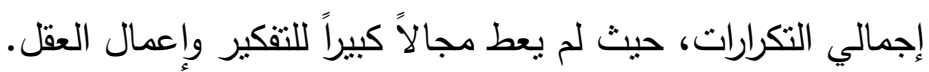
- جـاءت "الموضـوعية" في المرتبـة الخامسـة بنسـبة تكـرار (10 , 7\%) مـن إجمالي التكرارات، حيث برزت في طريقة عرض البيانات وتفسيرها، ولم يظهر في كثير من نواحي الكتاب المختلفة.

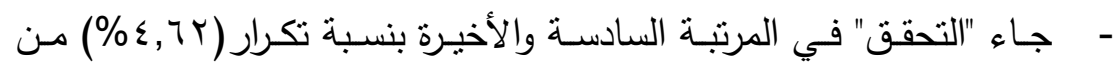
إجمالي تكرارات خصـائص المعرفة القائمـة على البحث العلمي، وهو مـا يتتاسب مـع هذه المرحلة السنية، وعدم تمكنها من التحقق بشكل كبير في

$$
\text { كثير من الأمور - من هده }
$$

\section{ثالثًا: خصائص المعرفة القائمة على البــث العلهـي في المهنهج البهديد}

الاطور: اللغة العربية "اكتشف":

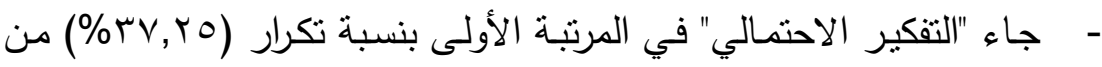
إجمـالي تكرارات خصـائص المعرفـة القائمـة على البحث العلمس، حيث

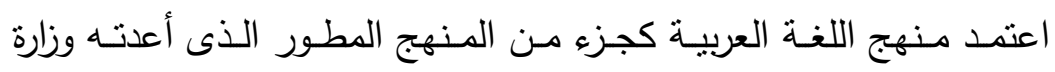




\section{المركن القومي للبحوث التبويةوالتنمية}

التربية والتعليم في عام 1/ ـ/9/ 1 ـ ع على الاكتشاف بشكل كبير ، وعلى

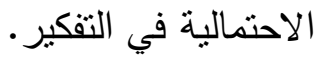

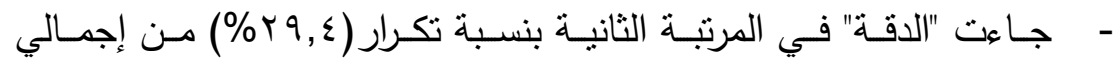

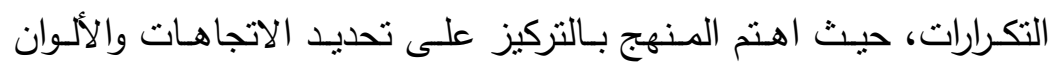
وفصول السنة.

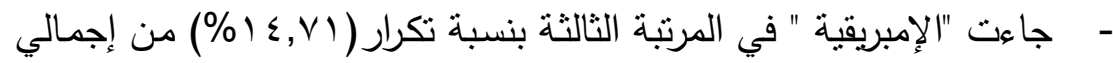

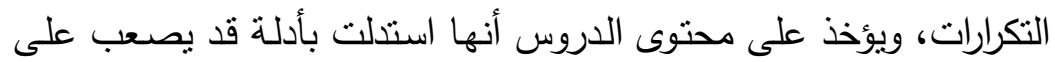
تلميذ في الصف الأول الابتدائي استيعابها. - جاءت "الموضوعية" في المرتبة الرابعة بنسبة تكرار (^,^9\%) من إجمالي

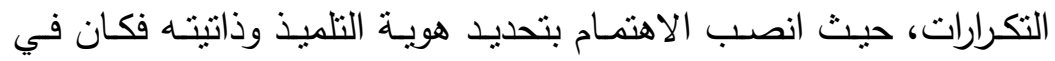

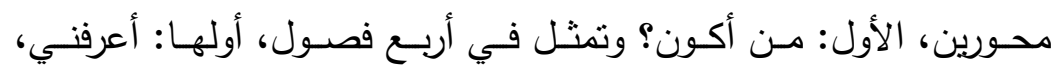
والثاني: شجرة العائلة، والثالث: من نحن؟، والرابع: مجتمعنا، بينمـا جـاء المحور الثالث بعنوان: العالم من حولي، واشتثل على أربعة فصول، أولها: عن بيئتنا، والثاني: تجول في البيئة، بينما الثالث عن: زراعة الغذاء في

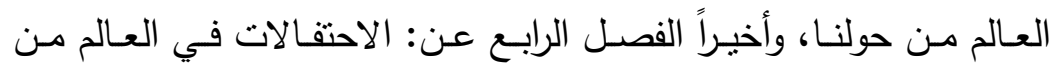
حولنا. وتتمي لدى التلمبذ الذاتية والأنا.

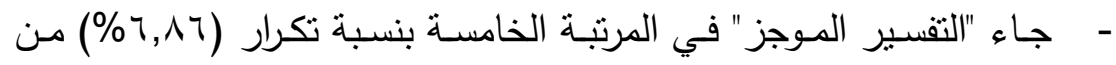
إجمـالي التكـرارات، حيث اهتم الكتاب باستـعراض المعلومـات بثـيء مـن

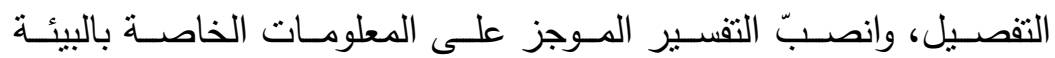
والصحة والبيئة العالمية، وهو الثكل المطلوب؛ لأنَّ التلميذ في هذه السن الصغيرة لا يمكنه إدراك الكثير من الأمور، إذا تمّّ التوسع في استعراضها. 


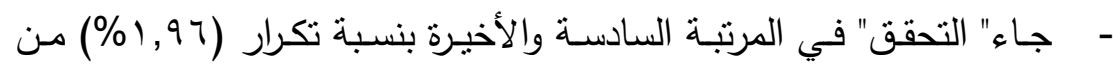
إجمالي نكرارات خصائص المعرفة القائمة على البحث العلىي، على الرغم من كونـه منهجًا مطورًا وأهميـة خاصية التحقق كأهم خصـائص المعرفـة القائمة على البحث العلمي، إلا أنَّ هذا المنهج لم يهتم بهذه الخاصية في

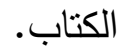

من الملاحظ بصفة عامة التالي:

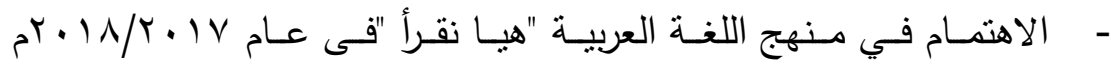

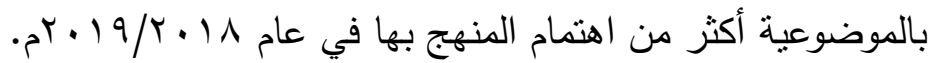

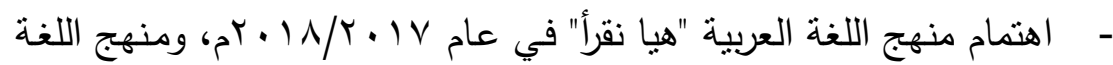
العربية "تواصل". و "اكتشف" فى عام 1 ـ ـ 9/9 1 ـ זم بخاصية "الدقة". - لم تهنم هذه المناهج بـ"التحقق"، وذلك على الرغم من أهمية هذه الخاصية في جميع المراحل التعليمية وجميع المقررات. - اهتمت الكتب بـ"التفسير الموجز" بنسب متقاربة عدا اللغة العربية "تواصل"

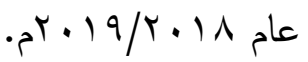

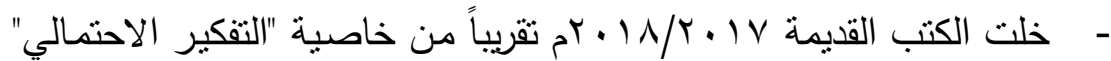

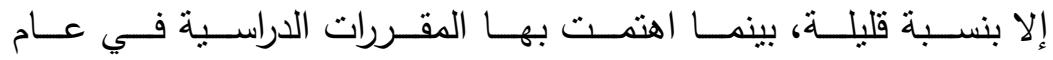

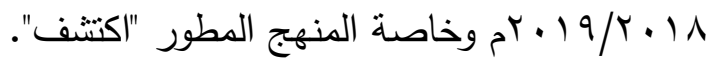

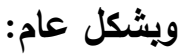

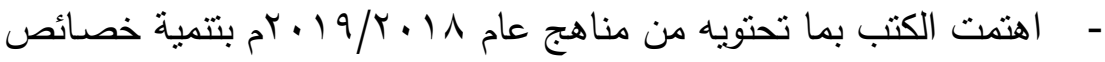
المعرفـة القائمسة علـى البحـث العلمـي بثـكل أكبـر مـن اهتمامهـا عـام

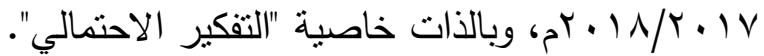




\section{المركن القومي للبحوث التبويةوالتنمية}

- يؤخذ على مـا تََّّ من تطوير عدم الاهتمـام بتتميـة خاصية "التحقق" على

$$
\text { الرغم من أهميتها الكبيرة. }
$$

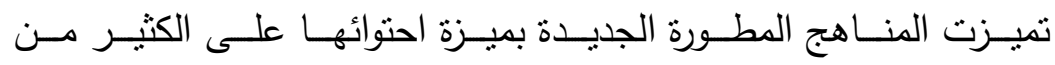
الموضوعات والعلوم المتتوعة ما بين اللغة العربية والعلوم والدراسات بشكل مبسط

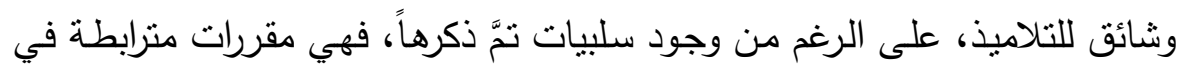
ذاتها" " فالحواجز بين المواد الدراسية يسيطر على أسلوب المعلم فمعلم للجغرافيا وآخر للتـاريخ، وفي ظل الانفجـار المعرفي المتزايد، وظهـور مـواد أخرى جديدة تضاف إلى ما يحمله المتعلم، والمعلم من أعباء وهذا يصعب المههة على خبراء

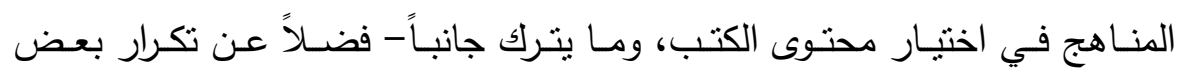
موضوعات الكتب بالصف الواحد والموضوع الواحد لعدة موضوعات فرعية للتلميذ،

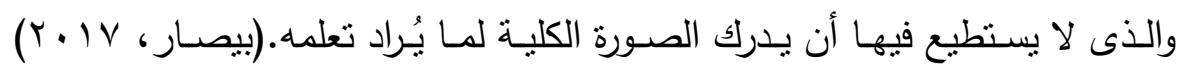

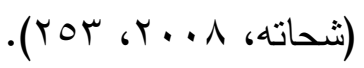

ثانياً: مرحلة التعليم الابتدائي (الصف السادس الابتدائي) (خصـائص المعرفـة القائمـة على البحث العلمـي في مـادتي اللغـة العربيـة، لعـام

$$
\left(b^{r+19 / r \cdot 11}\right.
$$

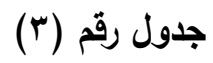

\begin{tabular}{|c|c|c|c|c|}
\hline \multicolumn{3}{|c|}{ اللغة العربية } & خصائص المعرفة القائمة & م \\
\hline الترتيب & $\%$ & ك & التكرار/ النسبة & \\
\hline السادس & $\% \vee, \vee ०$ & 11 & الموضوعية & 1 \\
\hline
\end{tabular}

يوضح خصائص المعرفة القائمة على البحث العلمي في الصف السادس الابتدائي

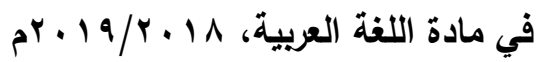

sor. 


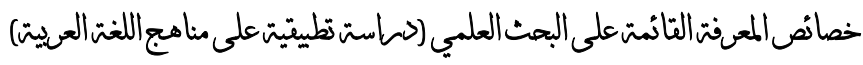

\begin{tabular}{|c|c|c|c|c|}
\hline الثالث & $\% \backslash \wedge, \mu \backslash$ & Y & الدقة & r \\
\hline الأول & $\% r \leq, 70$ & o r p & التحقق & $r$ \\
\hline الرابع & $\% 14, r$ & $r r$ & التفسير الموجز & $\varepsilon$ \\
\hline الخامس & $\% 9,10$ & Ir & الإمبريقية & 0 \\
\hline \multirow[t]{2}{*}{ الثاني } & $\%$ rr, q & r & التفكير الاحتمالي & 7 \\
\hline & $\% 1 \ldots$ & $1 \leqslant r$ & مج & \\
\hline
\end{tabular}

يتضح من الجدول السابق ما يلى:

- جاء "التحقق" كخاصية من خصائص المعرفة القائمـة على البحث العلمي

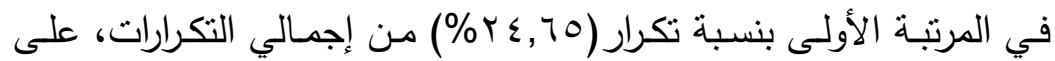
الرغم مـن أنَّ هذه الخاصية موجـودة بطريقـة شكلية غير عميقة؛ لأنها مذكورة ومكررة في الأهداف الموجودة أول كل درس، ولكنها ليست مفعّلة بالثكل الكافي داخل محتوى الدرس.

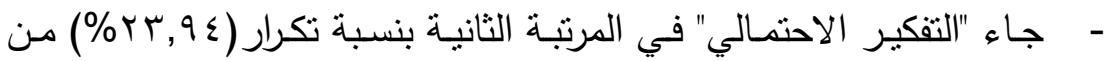
إجمالي التكرارات، حيث لوحظ أنَّهَ في كل درس تقربياً يطلب من التلميذ أن يضع عناوين أخرى للدرس، وهو ما ينمي لديه خاصية التفكير الاحتمالي، وهى إحدى خصائص البحث العلمي.

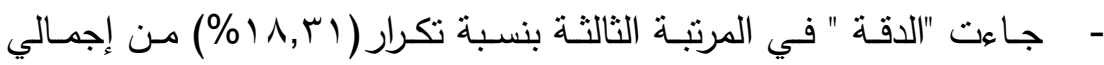
التكرارات، وقد برزت في الأهداف حيث يطلب من التلميذ تحديد الأفكار الرئيسة والفرعية، وتحديد السبب ونتيجته.

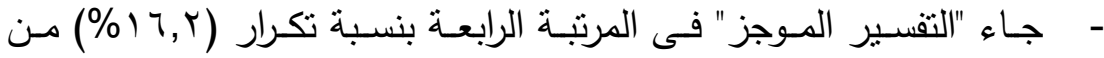
إجمالي التكرارات، على الرغم من أنَّ تتفيذ الأهداف المطلوبة في أول كل درس يتطلب شرح وتقصيل أكبر من التفير الموجز . . $\leqslant \leqslant$. البحث التربوي 


\section{المركن القومي للبحوث التبويةوالتنمية}

- جـاءت "الإمبريقيـة" و "الموضـوعية" فـي مـرتبتنين متــأخرتين هـــا المرتبــة

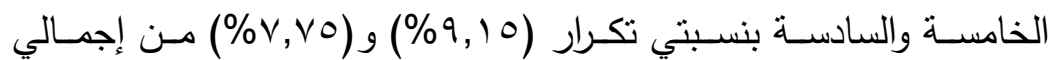
التكرارات على التوالي، على الرغم من أهمية هاتين الخاصبتين في تتمية خصائص المعرفة القائمة على البحث العلمي.

ثالثًا: هرحلة التعليم الإعدادي(الصف الثالث الإعدادي)

جدول رقم (ع)

يوضح خصائص المعرفة القائمة على البحث العلمي في الصف الثالث

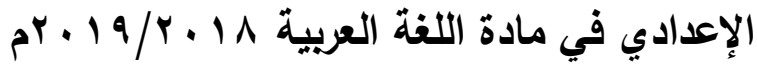

\begin{tabular}{|c|c|c|c|c|}
\hline \multicolumn{3}{|c|}{ اللغة العربية } & خصائص المعرفة القائمة على البحث & r \\
\hline الترتيب & $\%$ & ك5 & التكرار والنسبة & \\
\hline 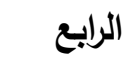 & $\% \backslash 0, \leqslant r$ & ro & الموضوعية & 1 \\
\hline السادس & $\% 1 \cdot, \leqslant 9$ & iv & الاقة & $r$ \\
\hline الثالث & $\% \backslash \vee, \curlyvee \wedge$ & YA & التحقق & $r$ \\
\hline الأول & $\% r \Delta, r)$ & $\leqslant 1$ & التفسير الموجز & $\varepsilon$ \\
\hline الثاني & $\% \backslash \vee, q$ & rq & الإمبريقية & • \\
\hline
\end{tabular}

.$£ 00$. 


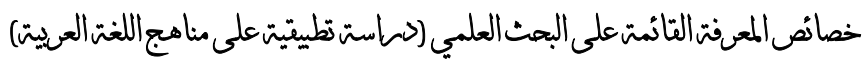

\begin{tabular}{|c|c|c|c|c|}
\hline$\% 1 r, 01$ & r & (التفكير الاحتمالي & \\
\hline & $\% 1 .$. & $1 r$ & \\
\hline
\end{tabular}

يتضح من الجدول السابق ما يلى:

1 - خصائص المعرفة القائمة على البحث العلمي في الصف الثالث الإعدادي

في مادة اللغة العربية: - مان

- جـاء " التفسير المـوجز" في المرتبـة الأولـي مـن إجمـالي تكـرارات خصـائص

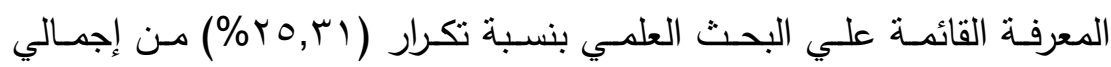
التكرارات، حيث اعتمدت نسبة كبيرة من الدروس علي شرح المحتوى بشكل

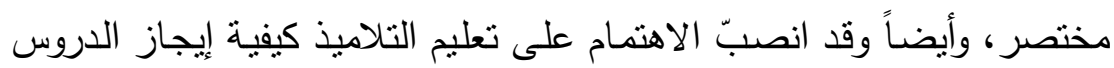
في فقرات أو حتى عناوين موجزة.

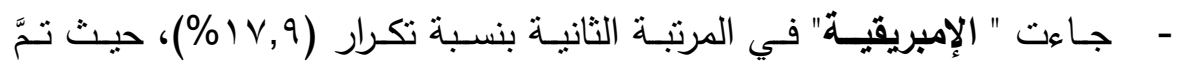
الاسترشـاد بالكثير من الصور الفوتوغرافية المعبرة أحياناً وغير المعبرة أحيانـاً كثيرة، (فمثلا في عنوان الكتاب نجد استشـهاداً بصورة تلميذ يفتح كتاباً علي حروف لغـة انجليزيـة على الرغم من كون هذا الكتاب لغـة عربيـة وليس لغـة انجليزبة) وأيضاً داخل الكتب توجد صور كثيرة غير معبرة بشكل حقبقي عمَّا

$$
\text { بداخل الدرس. }
$$

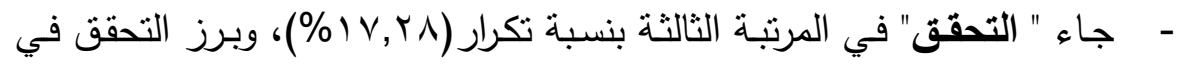
إعادة السؤال بأكثر من صيغة مختلفة تؤدي في النهاية لنفس الإجابة ونفس

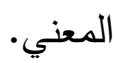
- جاءت " الموضوعية" في المرتبة الرابعة بنسبة تكرار (سع,0 (\%)، وبرز ذلك بشكل واضـح في مقدمة الكتاب، حيث تؤكد الوضوح في طريقة جمع بيانات الكتاب وتقسيرها وبشكل كبيـر، ولكن مـا جـاء داخل الدروس التي يحتويها 


\section{المركن القومي للبحوث التبويةوالتنمية}

الكتاب، لا تظهر هذه الخاصـية بشكل بـارز بـنفس الوضـوح الذى جـاء في المقدمة.

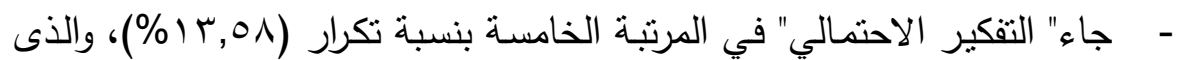
تمثنل بشكل كبير في أسئلة احتماليـة كثيرة، لا توجد لها إجابـة في الكتاب المدرسي، وتدعو إلي التفكير ، ولا يتسع وقت الحصص المدرسية لمناقشتها مـع المعلم، وتظل مبهمة لديه، إلا في حالة استخدام الكتب الخارجية، لما بها من تفسيرات وشـرح بشكل أكبر، وهو مـا يدعو إلبي اعتمـاد التلاميذ علي الكتب إلب الخارجية ونبذ الكتاب المدرسي.

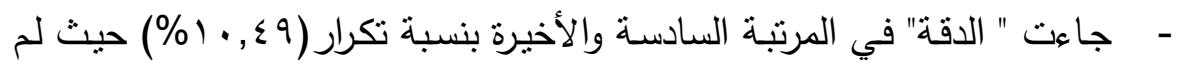
يهتم مؤلفو كتاب اللغة العربية في الصف الثالث الإعدادي بالدقة كثيراً، فتعدد المفهوم الواحد للدرس في بعض الأحيان، مثل (درس برايل)، الذى فقد بصره

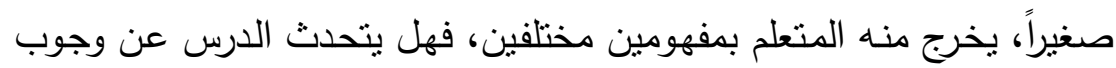

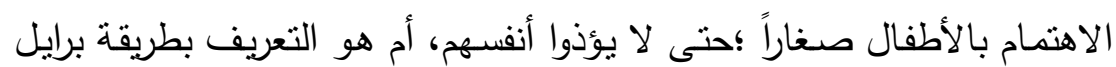
في الكتابة ؟ من الملاحظ بصفة عامة: - الاهتمام بخاصيتى "التفسير الموجز" و "الإمبريقية" في مادة "اللغة العربية"، وهو اهتمام في محله؛ لأن الطلاب ليسوا في حاجة إلى تفسير مفصل. - لم يتم الاهتمام بخاصيتى "الموضوعية" و" التفكير الاحتمال"؛ وذللك على الرغم من أهمية التفكير الاحتمالي في هذه المرحلة العمرية.

رابعًا: هرحلة التعليم الثانهي(الصف الثالث الثانوي العام)

جدول رقم (0)

يوضتح خصائص المعرفة القائمة على البحث العلمي 


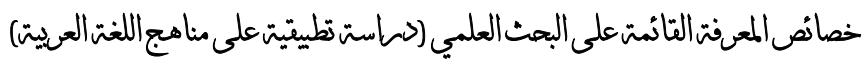

في الصف الثالث الثانوي العام في اللغة العربية، لعام 1 ـ ـ 9/9 1 ـ م

\begin{tabular}{|c|c|c|c|c|}
\hline \multicolumn{3}{|c|}{ اللغة العربية } & \multirow{2}{*}{ خصائص المعرفة القائمة } & \multirow[t]{2}{*}{$\hat{\imath}$} \\
\hline الترتيب & $\%$ & ك5 & & \\
\hline السادس & $\% \curlyvee,\{\wedge$ & 11 & الموضوعية & 1 \\
\hline الرابع & $\% 10,99$ & vi & الدقة & r \\
\hline الخامس & $\% 1 \cdot, 1 \leq$ & $\leq 0$ & التحقق & r \\
\hline الثانى & $\% r \leqslant, 00$ & 1.9 & التفسير الموجز & $\varepsilon$ \\
\hline الأول & $\%$ ro, $q$ & 110 & الإمبريقية & 0 \\
\hline \multirow[t]{2}{*}{ الثالث الث } & $\% r \cdot, q 0$ & 94 & التفكير الاحتمالي & 7 \\
\hline & $\% 1 \ldots$ & $\leqslant \leqslant \leqslant$ & مج & \\
\hline
\end{tabular}

يتضح من الجدول السابق ما يلى:

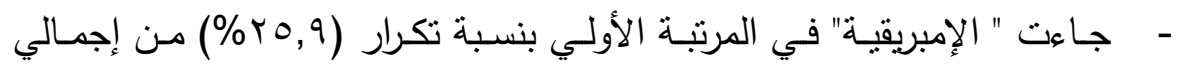
تكرارات خصائص المعرفة القائمة علي البحث العلمي، حيث اهتم مؤلفو الكتب إلي حدٍ مـا بتوظيف الأمتلـة والثواهد والأدلة في استعراض محتوى الدروس، واستخدام أدوات ربط منطقيـة وموضـوعية، والـربط بين الجو النفسي للشـاعر ووسائل التعبير في النص، واستخدام صور بيانيه، والاسترشـاد بالتجربة الثـعرية على ما يتم قراءته من نصوص. ولكن ما يؤخذ عليه أنَّ الاهتمام انصبَّ بنسبة كبيرة على الأهداف والتقويم، وليس على المحتوى. 


\section{المركن القومي للبحوث التبويةوالتنمية}

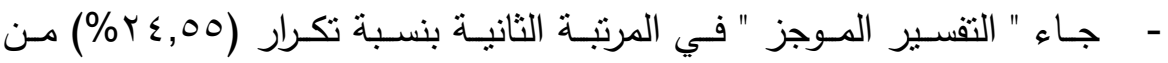
إجمـالي التكـرارات، حيـث انصـبَّ الاهتمـام على قدرة الطـلاب على منــاظرة الزملاء وتحديد الأفكار الزائدة والناقصـة في النص، واقتراح عنـاوين مختصرة لمحتوى الدروس، وإثراء المقروء بأفكار ابتكاربة، وتلخيص المقالات المقروءة،

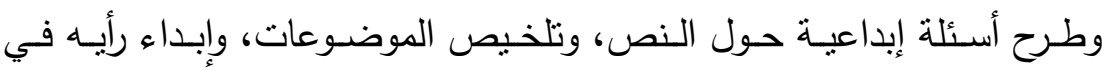
الموضـوعات، ومخاطبـة المسـتمعين بتعبيـرات مناسـبة، والتحـدث عـن الفكـر المحوريـة، وتعـرف نشـأة المـارس الثـعربة المختلفـة بشـكل مختصـر ، وتحديد الفكر الرئيسة، واقتراح عناوين للنصوص، واستتناج الفكر الرئيسة، وكتابة بحث مختصـر عـن أهميـة شـيء مــا، كـالقراءة وغيرهـا.....، وإثراء المقـروء بفكـر ابتكارية، وتلخيص بعض المسرحيات، وكل ذللك من التقسير الموجز • - جـاء "التفكير الاحتمـالي " في المرتبـة الثالثة بنسبة تكرار (90, • ب\%) مـن إجمـالي التكـرارات، مثـل: الاهتمـام بالـدلالات غيـر المباثـرة وطـرح الأسـئلة الإبداعيـة التي تحتمل التفكير ، وإثراء المقروء بأفكار ابتكاريـة، وتتظيم الفكر حسب رؤيته، والتتبؤ بفكر الموضـوع بعد الاسـتماع إلى عنوانـه، والاسـتتناج المتمثل في استتناج العوامل في درس ما، والتي ساعدت الطلاب على الاتجاه

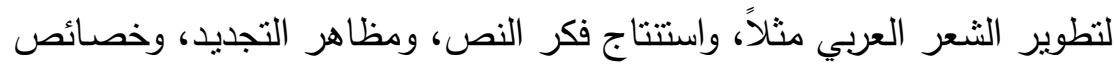

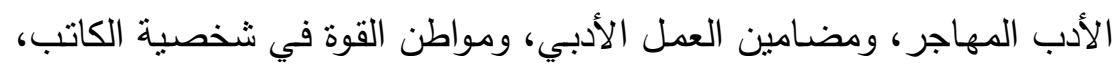

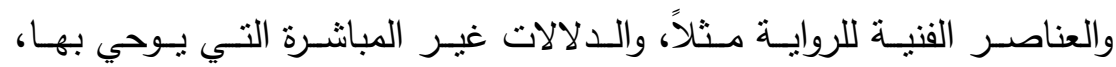

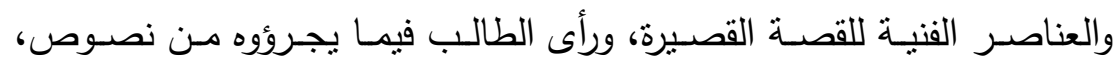
واستتناج عناصر التجربة الثعرية. - جـاءت " الدقـة" فـي المرتبـة الرابعـة بنسـبة تكـرار (0,99 (1\%)، حيـث اهـتم المؤلفون في أهداف الكتاب بتحديد الاتجاه الفكري للمتحدث، واستخدام أدوات 
الـربط، وكتابـة مقـالات فـي موضـوعات معينـه، وتصـنيف الجمـل المنطقيـة

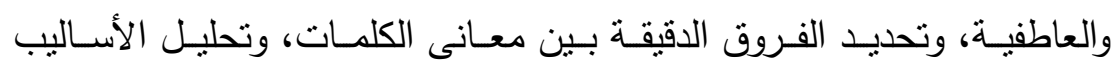
والتراكيب اللغوية، وتحديد موقف الطلاب من مؤلف الكلمات التي يستمع إليها

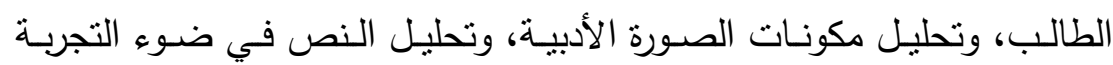
الثـعرية، وتحديد الخصـائص الفنيـة لمدرسـة مـا، وتعبيره عن رأيسه في المعاني

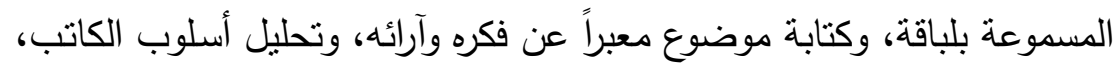
وتحديد مفهوم القصة، وتوضيح سماتها واتجاهات المسرحية وأسسها.

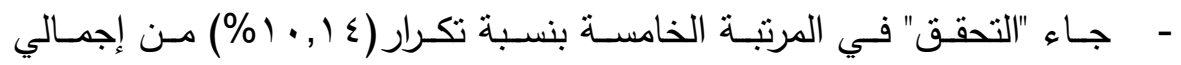
التكرارات، في تحقق الطالب فيمـا يقرأ عبر الوسـائط التكنولوجيـة المتعددة، وتتظيم الأفكار حسب رؤيته، والتحقق من المفهوم الصحيح للعلوم في الإسـام، والتحقق من دور أحمد شوقي وجيل التطوير في الإحياء والبعث، والتحقق من مناسبة النص، والتحقق في الموازنة بين أكثر من عمل أدبى، والتحقق بتحديد الفروق الدقيقة بين معـانى الكلمـات التي اســمع إليهـا، والتحقق بـالتمكن مـن مهارات التفكير الناقد، والتحقق بالموازنة بين الرواية والقصـة القصبرة، والتحقق مـن الموازنـة بـين الآراء بطريقـة موضــوعية، والتحقـق بالتواصـل مـع آليـات الحكومة الإككترونية.

وعلي الرغم من كل ما سبق، يمكن القول أنَّ نسبة الاهتمام بخاصية "التحقق"

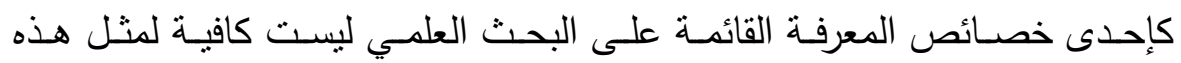
المرحلة، والتي من المفترض أنَّ الطالب أصبح بالانفتاح العقلي الذى بؤهلـه للتحقق من كثير من المعلومات، ولا ينتظر من يمليها عليه دون التأكد من صحتها.

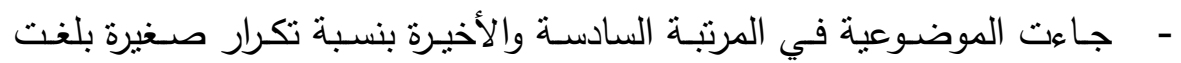

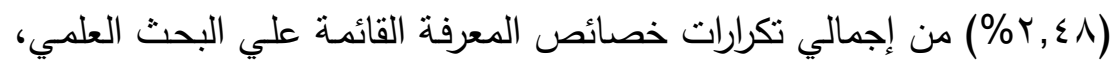




\section{المركن القومي للبحوث التبويةوالتنمية}

مثل: بعض الموضـوعات القليلة عن: تقدير احترام الإسـلام لحقوق الإنسـان والتسـامح وإعمال العقل، وتقدير العلم والعلمـاء بطريقة حياديـة، وكتابـة مسودة

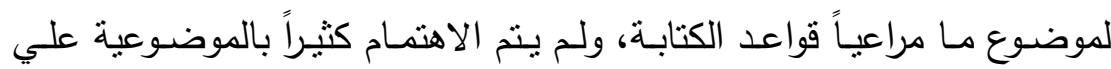
الرغم من أهمية تعليمها للطلاب في هذه المرحلة.

تشير نتائج البحث إلى أن هنالك تفاوت في نسب تكرارات وجود أبعاد البحث العلمي في مقررات اللغـة العربية في الصفوف الدراسية محل البحث، وهذا ينبئ عن عدم وجود مصفوفة مدى وتتابع لهذه المهارات وتوزيعها عبر الصفوف الدراسية، فالاهتمام بتطوير المقررات الدراسية في الصفوف الأولية من الأول إلى الثالث الابتدائي، لـم يماتلـهـ تطوير في الصـفوف الأعلى، أو في المراحل التعليمية الأعلى الإعدادية والثانوية في ضوء مهارات البحث العلمي. وبرجع ذلك أيضاً لعدم وجود تخطيط علمي عبر مقررات اللغة العربية في الصـفوف المختلفـة بتـدرج يتتاسـب مـع خصـائص المتعلمين، فالاهتمـام الأساسي بالمهارات اللغوية ومنها المهارات النحوية أو غيرها من المهارات. وتتفق نتيجة البحث الحـالي مـع دراسـة كل من: الضبة(r ا ـ r) البنـا

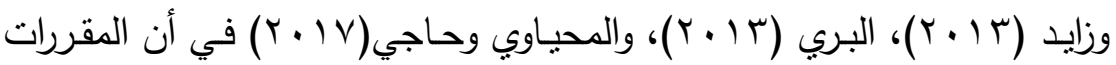
الدراسية تحتوي نسب منخفضـة من المهارات والموضـوعات التي يتت تحليلها، وأن هناك تفاوتات في هذه النسب، لعدم وجود روئية واضحة لتوزيع المهارات على الموضوعات الدراسية التي يدرسها الطلاب. في ضوء نتائج البحث، يوصي البحث بالآتي: - مراعـاة تدرج خصـاص المعرفـة القائمـة على البحث العلمي بمـا يتتاسب مـع المرحلة العمرية للتلاميذ في المقررات الدراسية التي يدرسونها. 


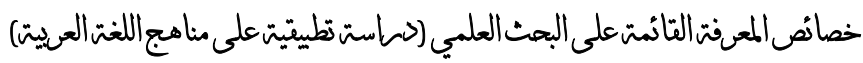

- - التوسـع في الأنشـة العلميـة البحثيـة في المقررات الدراسية للغـة العربيـة بحيث تشـل: البحث في الانترنت عن معلومـات لغويـة، أو التحقق من الن

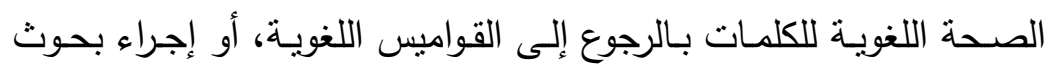
ودراسات أو تقارير عن دلالات لغوية لكلمات مختلفة. - الاهتمـام بإيجـاد خاصية التحقق في المقررات الدراسية للغـة العربيـة في الصفوف المختلفة، وقيام المتعلم بالعمليات العلمية والبحثية اللغوية. - إنشـاء معامـل للغـة العربيـة في المدارس، بحيث يتـاح للتلاميذ الممارسـة اللغوية الصحيحة، والتجريب العلمي بطريقة عملية. - - تدريب المعلمين على مهارات البحث العلمي، واهتمام مشرفي اللغة العربية

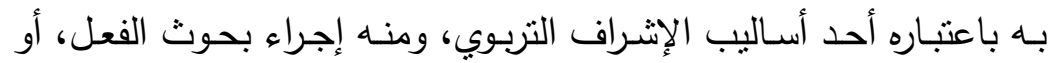

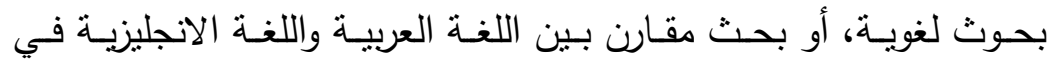

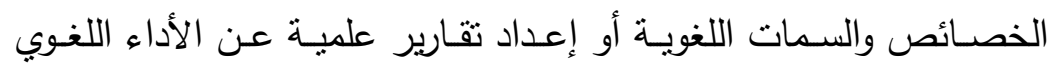
لطلابـه أو إعداد تقرير علمي لتحسين الأداء اللغوي للطلاب، ويتن تقييم المعلمين من خلال هذه البحوث.

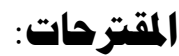

$$
\text { إجراء بحوث عن: }
$$

- تضـمين مهارات البحـث العلمي في منـاهج اللغـة العربيـة في الصـفوف الدراسية المختلفة.

- برنامج تدريبي لتتمية مهارات البحث العلمي وبحث الفعل لدى معلمي اللغة العربية. - - مدى استخدام مشـرفي اللغة العربيـة لمهارات البحث العلمي في الإشراف التربوي، وتدريبهم للمعلمين على مهاراته. 


$$
\text { المركن الثومي للبحوث التبويةوالنمية }
$$

\footnotetext{
- تقييم أداء معلمي اللغة العربية في ضوء مهارات البحث العلمي. - أثـر برنـامج مقتـرح لإكسـاب تلاميـذ المرحلـة الابتذائيـة مهـارات التفكيـر العلمي.
} 
خصانص المعنتا التانتت على البجث العلمي (هاست تطيتيت على مناهج اللغتا العييت)

\section{المراجع}

\section{المراجع العربية:}

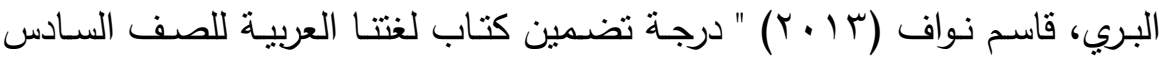
الأساسي في الأردن لمهارات التفكير الناقد: دراسـة تحليلية "مجلة العلوم التربويـة والنفسـية"، مـجـ ع (، ع ع، جامعـة البحـرين - مركـز النشـر العلمي.

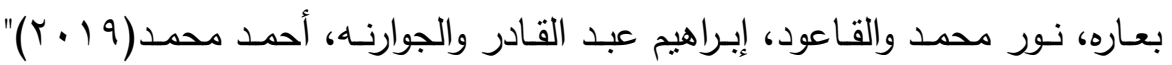
درجة تضمين كتب التاريخ للمرحلة الأساسية العليا في الأردن لمعارف

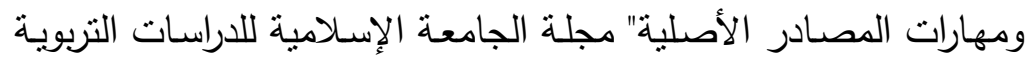

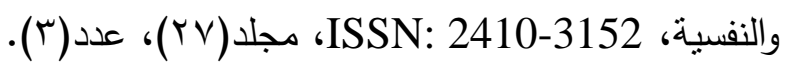

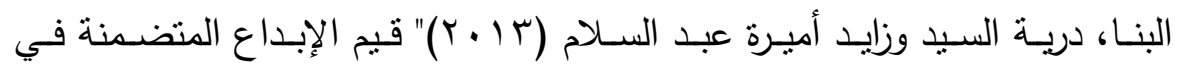
مقررات اللغـة العربيـة والدراسـات الاجتماعبـة بالمرحلـة الابتدائيـة "دراسـة

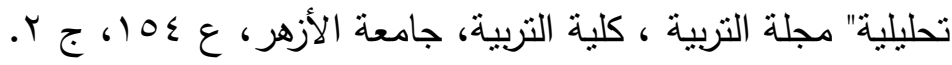
بيصسار، فرح عبده(Y V V V)" من واقع مشكلات التعليم"، المكتبة العصـرية للنشـر والتوزيع.

جرادات، هاني محمود (r r r r) "العلاقة بين التفكير الاحتمـالي والتفكير التتاسبي لاى طلاب المرحلة الثانوية في محافظة وادي الدواسر " المجلة العربية

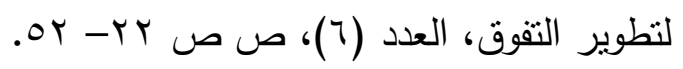

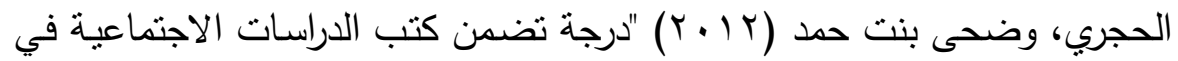
الصفين الحادي عشر والثاني عشر في سلطنة عمان لمهارات البحث العلمي" رسالة ماجستير ، عمادة الدراسات العليا، جامعة مؤنة. 


\section{المركن القومي للبحوث التبويةوالتنمية}

الديات، أفنان عبد الحافظ والحديدي، منى صبحي (9 ( ب)" درجة تطبيق معلمي غرف المصـادر في الأردن لاستراتيجيات تدريس القراءة المسندة بنتائج البحث العلمي واتجاهـاتهم نحو الممارسـات المسندة إلى الأدلـة العلميـة" ISSN:2410- مجلـة الجامعـة الإسـلامية للدراسـات التربويـة والنفسـية

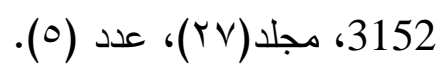

رزوقي، نعيمة حسن جبر (r )"رؤية مستقبلية لدور اختصاصي المعلومات في إدارة المعرفـة"، إدارة المعلومـات في البيئـة الرقميـة: المعـارف والكفـاءات والجـودة، وقـائع المـؤتثر الثالــث عثـر للاتحــاد العربــي للمكتبــات والمعلومات (تونس المنظمة العربية للتربية والثقافة والعلوم.

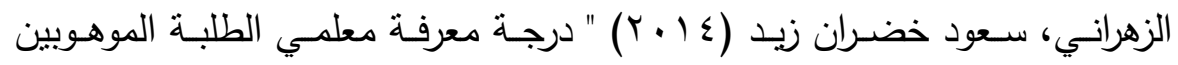
بمهارات البحث العلمي بمحافظة الطائف " رسالة ماجستير ، كلية التربية، جامعة الباحة، السعودية.

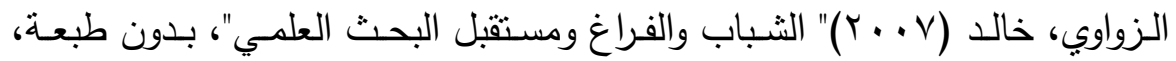
الإسكندرية مؤسسة حورس.

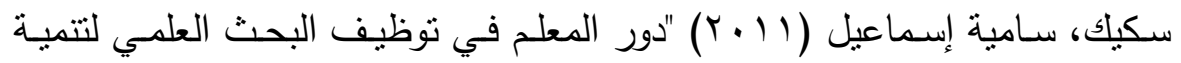

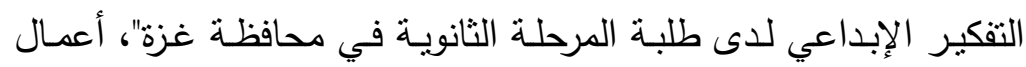
مؤتمر البحث العلمي: مفاهيمه - أخلاقياته - توظيفه، المنعقد في قاعة الإعة المؤتمرات الكبرى بالجامعة الإسلامية في الفترة • او ا 1 مايو.

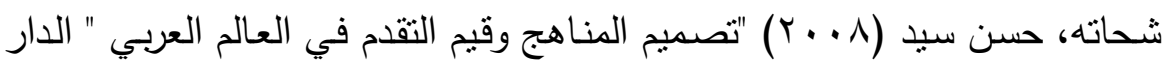
المصرية اللبنانية، القاهرة. 


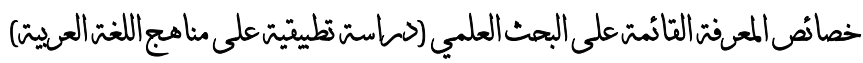

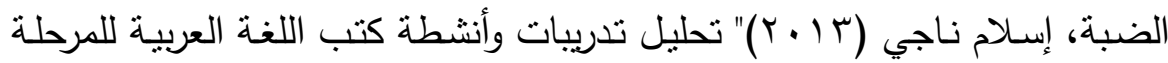
الأساسية الدنيا في ضوء مهارات التفكير فوق المعرفي وتصور مقترح

$$
\text { لإثرائها" رسالة ماجستير ، الجامعة الإسلامية - غزة. }
$$

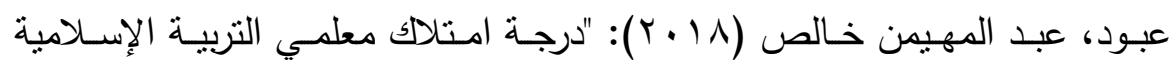

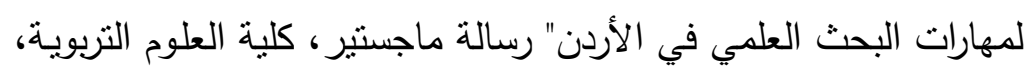
جامعة آل البيت، الأردن.

العصيمي، سامية(2014) "فاعلية برنامج تدريبي مقترح في تتمية مهارات البحث العلمي لدى معلمات العلوم الطبيعية وأثره على التفكير العلمي لدى طالبات المرحلة الثانوية بمحافظة الطائف التعليمية".رسالة دكتوراه غير ودرة منشورة كلية التربية، جامعة القرى، المملكة العربية السعودية.

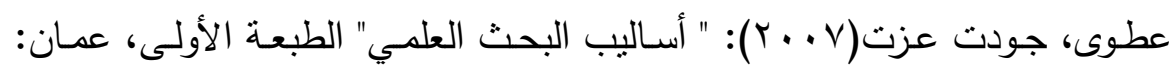
دار الثقافة للنشر والتوزيع.

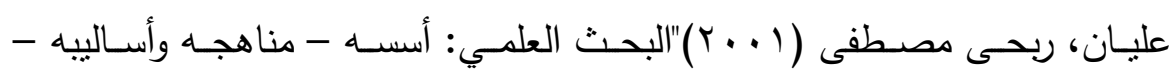
إجراءاته"، دار بيت الأفكار الدولية، عمان، الأردن.

عوض، فايزة السيد (9 ( • ( ) " مداخل تعليم اللغة العربية: روئية تحليلية" مركز الملك عبد الله بن عبد العزيز لخدمة اللغة العربية.

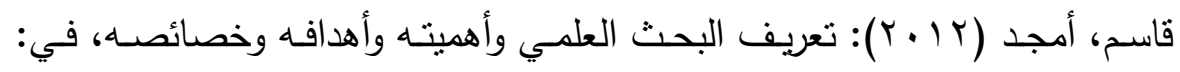

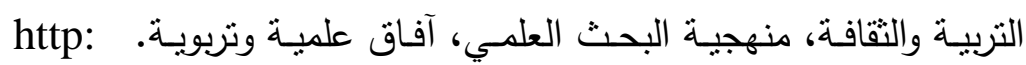
//al3loom.com/?p=4018

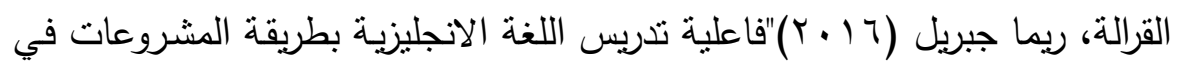

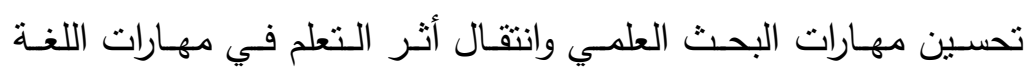




\section{المركن القومي للبحوث التبويةوالتنمية}

الانجليزيــة لـدى طالبـات الصـف الثـامن الأساسـي فـي الأردن" رسـالة

دكتوراه، كلية الدراسات العليا، جامعة العلوم الإسلامية العالمية.

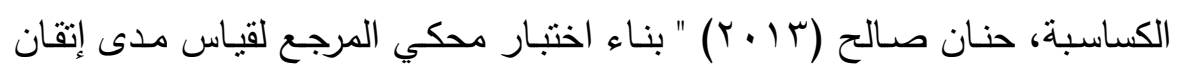
طلبـة الدراسـات العليـا في جامعـة مؤته لكفايـات البحث العلمي" رسـالة ماجستير غير منشورة، جامعة مؤته، الأردن.

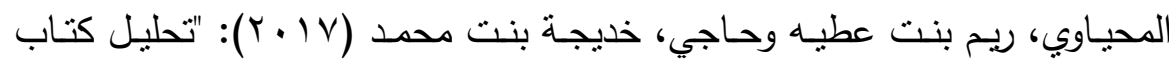

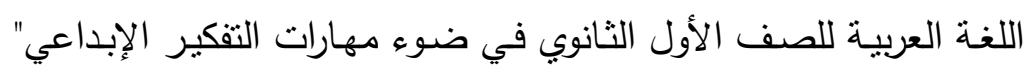

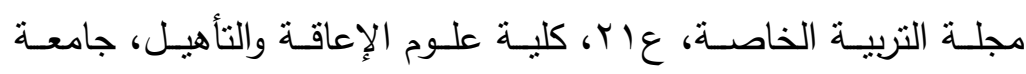
الزقازيق.

المنظمة العربية للتربية والثقافة والعلوم، (9 1 ـ ب): " النهوض باللغة العربية وإغناء المحتوى العربي" WwW.alecso.org

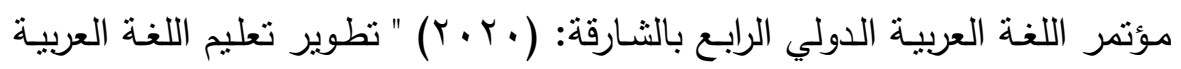

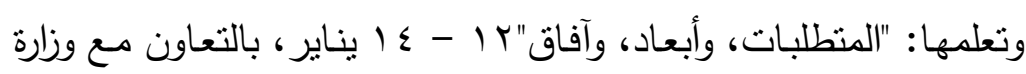
التربية والتعليم وجامعة الثـارقة قسم اللغة العربية - كلية الآداب والعلوم الإنسانية والاجتماعية.

الناقة، صلاح أحمد والعامودي، نضال رسمي (10 ب ب): " أثز إثراء محتوى منهاج العلوم بمضـامين الإعجاز العلمي في القرآن الكريم في تتميـة مهارات

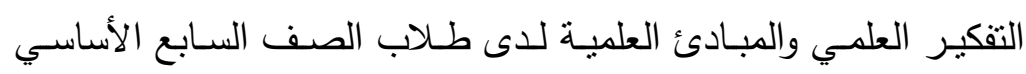

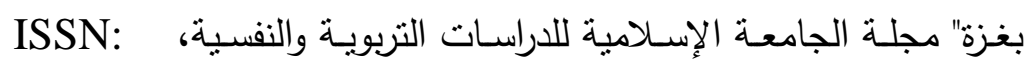

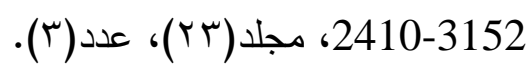

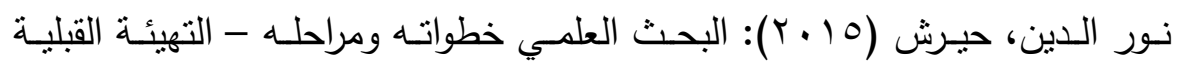
للباحث، تمتين أدبيات البحث العلمي، مركز جيل للبحث العلمي، لبنان 
طـرابلس، فرع أبسى سـمراء، الملتقى العلمي المشـترك الأول مـع المكتبـة

الوطنية الجزائرية،، 9 ب ديسمبر، 3SSN 2409-3963

الهنداوي، زينب عبدالرزاق عبود(7 ( ـ ب): مفهوم البحث العلمي، كلية الادارة

http: والاقتصاد، جامعة بابل، العراق

//www.uobabylon.edu.iq/uobcoleges/lecture.aspx?fid=

$9 \&$ lcid $=57392$

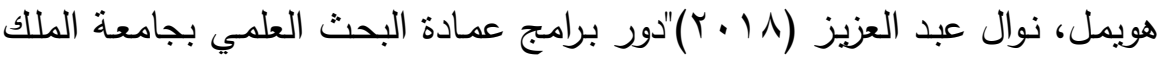
سعود في تتميـة المهارات البحثيـة لدى الطالبات " مجلة العلوم التربويـة

والنفسية ISSN: 2518-5780، فبراير، العدد الرابع، المجلد الثاني.

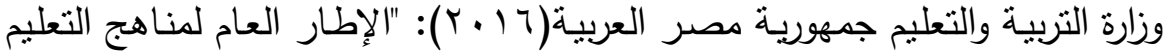

قبل الجامعي في مصر".

وزارة التربية والتعليم العالي فلسطين، (10 ـ ب) " دليل مشروع نشر ثقافة البحث

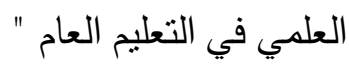

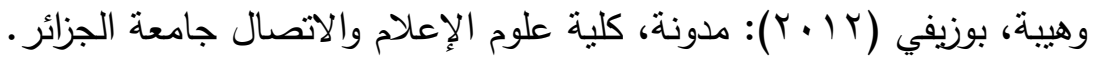
http: //bouzifiwahiba.over-blog.com/article-112995563.html

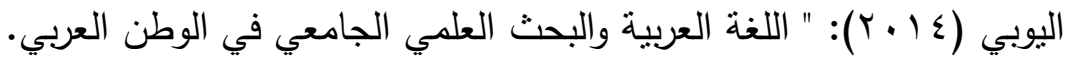
https: //www.hespress.com/writers/105341.html"

Abell, S.K. (2007). Research on Science Teacher Knowledge. In S.K. Abell and N.G. Lederman (Eds) Handbook of research on Science Education (pp 1105 - 1149). New Jersey: Lawrence Erlbaum Associates Inc. Ameh, C., \& Gunstone, R. (1985 Alakwe, Kizito Ogedi,(2017)Positivism and Knowledge Inquiry: From Scientific Method to Media and 
Communication Research, Science Arena Publications Specialty Journal of Humanities and Cultural Science Available online at www.sciarena.com, Vol, 2 (3): 38-46, School of Media and Communication, Pan-Atlantic University, Lagos, Nigeria.

Arzi, H.J. \&White, R. T. (2007). Change in Teachers' Knowledge of subject matter: A 17- year longitudinal study. Science Education.

Balakumar,Pitchai\& Jagadeesh, (2011)The 63rd Annual Conference of the Indian Pharmaceutical Congress (IPC) was held in Bengaluru, India, from 16 to 18 December. '. The conference was preceded by a 2-day workshop, titled "The Basic Concepts of Scientific Research and Scientific Communication.

Borko, H. (2004). Professional development and teacher learning: Mapping the terrain. Educational Researcher.

Çaparlar,Özhan\& Dönmez (2016) What is Scientific Research and How Can it be Done, , Clinic of Anesthesiology and Reanimation, Dışkap1 Yıldırım Beyazit Training and Research Hospital, Ankara, Turkey Turk J Anesthesia rename.

Carrillo,Francisco Javier, (2015)Knowledge-based development as a new economic culture, Journal of Open Innovation: Technology, Market, and Complexity December,. Journal of Open Innovation: Technology, Market, and Complexity, Coverage, Volume 1 - Volume 4Online ISSN, 2199-8531, Publisher, Springer Singapore. 
Casey, Denny. (2012) The Nature of Science, Ph.D, Virginia Science Standards Institute.

Encyclopedia Britannica "Innate idea", www.britannica.com

Eric, \& Casselman , R. (2011)Innovation as A Knowledgebased outcome, Version March, Journal of Knowledge Management.

Hegarty, Seamus,(2001): Characterizing the Knowledge Base in Education, Foray has offered an analytical framework and a set of indicators designed to illuminate the measurement and application of knowledge in a number of sectors. This paper offers a response from the particular perspective of the education sector.

Heywood, D.S. (2007) Problematizing science subject matter knowledge as a legitimate enterprise in primary teacher education. Cambridge Journal of Education.

iSessa , A.(2000) Changing minds Computers, Learning, and Literacy. Cambridge, Massachusetts: The MIT Press

khourey-Bowers, \& Fenk, (2009). Influence of constructivist professional development on chemistry content knowledge and scientific model development. Journal of Science Teacher Education, 20, 437 457

National Research Council (2002) Scientific Research IN Education, Center for Education, Division of Behavioral and Social Sciences and Education, Committee on Scientific Principles for Education Research, National Academy Press Washington, DC 20418.

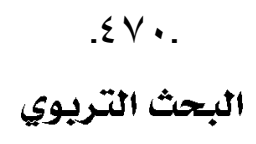


Ratcliffe, M., \& Millar, R. (2009) Teaching for understanding of science in context: Evidence from the pilot trials of the Twenty-First Century Science courses, Journal of Research in Science Teaching.

Review wood, David.(2018) The Role of Scientific Knowledge in Research \& Peer General Studies Science: Help \& Review / Science Courses ,https: //study.com/academy/lesson/the-role-of-scientificknowledge-in-research-peer-review.html

Rollick, Marissa, (2017), Learning About Semi-Conductors for Teaching? The Role Played by Content Knowledge in Pedagogical Content Knowledge (PCK) Development, University of the Witwatersrand.

Rolnik ,Marisa,\& Logan, Mike(2014) Exploring Knowledge Learners Math and Science Teachers: Exploring Knowledge Editors Mathematics and Science Teachers: Vince Abingdon, Vanessa King of Education, University of Durham

shama, amit \&chunawala, (2011) Conference: episteme 4 Fourth international conference to review research on Science, Technology and Mathematics Education, At Homi Bhabha Centre for Science Education, TIFR, Mumbai, India

Towne, Lisa,\& Wise, Lauress L.(2004), Advancing Scientific Research In Education Committee on Center for Education, Division of Behavioral and Social Sciences and Education, the national research council of the national academes, the national academes press Washington DC, www.nap.edu

Venkat ,Hamsa,\& Rollnick (2014) Science teachers' content knowledge Exploring Mathematics and Science \&V). 


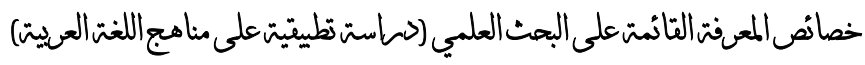

Teachers' Knowledge Abingdon, Vanessa Kind School of Education, Durham University, pp. 15 29.

Wang, J. (2004) Enhancing Elementary Science Teachers Knowledge of Teaching: The Case of Designing and Implementing an Instructional unit. International Journal of Science and Mathematics Education. 2, pp. 455-476.

Wood, A., \& Lewthwaite, B. (2008). Maori science education in Aotearoa New Zealand: aspirations and realities. Cultural Studies of Science Education, 3, pp. 625-662.

Ambusaidi, A. (2000). An investigation into fixed response questions in science at secondary and tertiary levels. PhD. Thesis. Glasgow, University of Glasgow.

Mohammed M. Mohammed Embark,( 2019) The impact of KWLH strategy on the development of methods of thinking and cognitive achievement of some vocabulary of scientific research, IUG Journal of Educational and Psychology Sciences (IUGJEPS) , Vol 8 No 2.

Ajidah, Ajidah (2017) The development of the educational book based on the scientific approach to the teaching of the Arabic language in the fifth semester at the Islamic primary school Salam Malang,Undergraduate thesis, Universitas Islam Negeri Maulana Malik Ibrahim. 